\title{
Salient Genetic and Proteomic Pathways in Glaucoma
}

\author{
Joseph W Eichenbaum* \\ Department of Ophthalmology and Pharmacology, Icahn School of Medicine at Mount Sinai New York, USA
}

\author{
*Corresponding author: Joseph W Eichenbaum, Adjunct Associate Professor of \\ Ophthalmology and Pharmacology, Icahn School of Medicine at Mount Sinai New \\ York, USA.
}

Received Date: August 03, 2020

Published Date: November 12, 2020

\begin{abstract}
Glaucoma, the second leading cause of blindness worldwide is a neurodegenerative disease, with or without elevated ocular pressure, exhibiting several different phenotypic presentations, which result in progressive visual field loss after compromise of retinal ganglion cells and their axons to the optic nerve and brain. Predominant clinical glaucoma types are primary open angle, POAG, angle closure, and congenital; secondary glaucomas are: psuedoexfoliaiton, pigmentary, neovascular, traumatic, iridoendothelial, and uveitic glaucoma. In each of these types of glaucoma, genetic, epigenetic, proteomic, environmental, and mechanical forces may converge as well to cause or advance the disease. Alternatively, but not necessarily in an independent fashion, stress related pathways of oxidative stress, inflammation, infection, trauma, immune reaction, neuro-degeneration and mutant genomic products can produce deleterious misfolded proteins, antibodies, and aggregate deposits in the trabecular meshwork, TM, raise the intraocular pressure and result in optic nerve damage and loss of vision. Examining the interplay of these stress pathways with genetic, epigenetic, proteomic, environmental and mechanical forces to gain some understanding of molecular causes of glaucoma is the goal of this paper.
\end{abstract}

Keywords: Glaucoma GWAS, Myocilin mutants/misfolded proteins, Oxidative stress, HSP, Inflammation, Immune/autoimmune response, Mitochondrial lysosome axis dysfunction, Autophagy pathways, Trabecular meshwork ECM dynamics, RGC/brain neuroprotection, Epigenetic role

\begin{abstract}
Abbreviations: AH: Aqueous Humor; ATP: Adenosine Triphosphate; Bcl-2: B cell lymphoma 2; CHOP: A multifunctional transcription factor in endoplasmic reticulum oxidative stress and protein misfolding; CLAN: Cross linked actin network; DARC: Detecting apoptosing retinal ganglion cell technique; ECM: Extracellular matrix; ELAM: Endothelial leukocyte cell adhesion molecule; EM: Electron microscopy; ER: Endoplasmic reticulum; GWAS: Genome wide association study; HSP: Heat shock protein; IOP: Intraocular pressure; JCT: Juxtacanalicular region of the trabecular meshwork; JNK: Jun N-Terminal Kinase; MAGP-1: Microfibril associated glycoprotein; MAP: Kinase mitogen activated protein kinase, increase ECM production in TM cells; ERK: Kinase extracellular; MAP: Microtubular kinase; MIP: Macrophage inflammatory protein; MITF: Microphthalmia associated transcription factor; MMP: Matrix metalloproteinase; MTORC-1: Mechanistic target of rapamycin complex overseas protein synthesis for Lysosome function; Myoc-OLF: Myocilin olfactomedin domain five-bladed $\beta$-propeller protein family; NAD: Nicotinamide adenine dinucleotide; NFKB: Nuclear factor kappa-light-chain-enhancer of activated B cells, major transcription factor for inflammation/immune modification in the cell; NMDA: N-methyl D Aspartate; NTG: Normal tension glaucoma; Nrf2: Nuclear factor erythroid 2, major oxidative stress transcription factor; PDS: Pigmentary dispersion syndrome; PERG: Pattern electroretinogram; PG: Pigmentary glaucoma; PI-3: Kinase phosphoinositide-3 kinase; PMEL: Premelanosome protein that may form physiologic amyloid beta protein in melanosomes; POAG: Primary open angle glaucoma; PTEN: Phosphatase and tension homologue; PTP: Mitochondrial permeability transition pore; PXG: Pseudoexfoliaiton glaucoma; PXS: Pseudoexfoliaiton syndrome; REST: Repression element silencing transcription factor; Retinal Ganglion Cell; Rho Kinase protein kinase modifying cell shape, size and adhesion; SC: Schlemm's Canal; SPARC: Secreted Protein Acidic Rich in cysteine, binds to ECM proteins and regulate matrix metalloproteinase expression; SMAD: 'Small Mothers against decapentaplegic homolog' literally but actually transcription factor which mediates TGF beta transduction or simply helps transfer cytoplasmic signals to nucleus to activate molecules like MAP or Rho kinase; TEK: Receptor tyrosine kinase; TGF: Beta transforming growth factor beta (signalling differentiation, proliferation, chemotaxis and fibrosis); TIMP 3: Tissue inhibitor of metalloproteinase; TLR4: Toll like receptor 4; TM: Trabecular meshwork; TNF: Tumour necrosis factor; TNFR: Tumour necrosis factor receptor; UPR: Unfolded protein response; VCAM1: Vascular adhesion protein; VEP: Visual evoked potential
\end{abstract}

\section{Introduction}

Glaucoma is a complex disease with many different phenotypes that can manifest over a lifetime. Childhood glaucoma, for example, also referred to as congenital or infantile glaucoma occurs in babies and young children. Although it is a rare condition, it may be 
inherited and is usually diagnosed within the first year of life by the elevated ocular pressure, abnormal drainage angle structure and excavated optic nerve. It develops from improper development of the eye's TM/SC (trabecular meshwork/Schlemm's Canal) drainage system before birth [1].

By comparison, recent work has suggested that typical alterations for open angle glaucoma, POAG, one of the leading causes of irreversible worldwide blindness, were observed in a subset of ocular normotensive Alzheimer's disease patients on Heidelberg Retinal Tomograph-3, (which photographically and statistically monitors: linear cup/disc ratio, cup shape measurement, rim area, rim volume, height variation contour, and mean retinal nerve fiber layer (RNFL) thickness) [2].

Thus, over a lifetime, different pathways from within the two large glaucoma defect categories of impaired aqueous outflow channels and nerve damage to percipient and conductive neural elements of the eye and brain have been implicated in the neurodegenerative glaucoma process [3].

From a historical perspective, trabecular meshwork, TM/ Schlemm's canal, SC, defects were primal to the development of elevation of intraocular pressure and optic neuropathy. However, in the last two decades the narrative has become more detailed with the elucidation of glaucoma category genes, proteins, and transcription factors in both the TM, and retinal ganglion cell, RGC, anatomic regions. These glaucoma category details encompass the language of RGC and TM cell survival after sustained oxidative stress from mutant derived and misfolded protein challenging mitochondrial sufficiency, provoking immune and inflammatory reaction, and leading to either repair/maintenance or apoptosis and cell death.

In this article I would like to first highlight some of the salient genes and proteins from each of these categories. SIX6, (retinal ganglion cell related), FNDCB3, FMNL2, (IOP, POAG related), CDKN2B-A (vertical cup/disc related), PLEKHA7, HGF, FERMT2, and GLIS, (narrow angle glaucoma related), ANGPT1, ANGPT2 and $V E G F-C$, (Schlemm's canal regulation through receptor tyrosine kinase), LOXYL1 (through the window of pseudoexfoliaiton glaucoma), and PMEL, ( a protein related to pigmentary glaucoma). These elements constitute the first section of the paper.

POAG, IOP, Cupping of the optic nerve, visual field defects, TM/Schlemm's canal outflow issues, pseudoexfoliaiton glaucoma and pigmentary glaucoma are the basic vocabulary of the ophthalmologist in first considering a diagnosis of glaucoma. Thus, genomic and proteomic correlates to these glaucoma characteristics and glaucoma types are discussed second.

Characteristic proteins from the aqueous humor, $\mathrm{AH}$, of glaucoma patients, associated with cell signalling, glycosylation, immune response, molecular transport, and lipid metabolism initiates the global protein or second sub-section of the paper.
Then, proteins of the TM extracellular matrix, myocilin, TGF beta, clusterin, amyloid, heat shock proteins, Toll receptors, interleukins, and ubiquitins are reviewed. In their individual and concerted efforts in RGC and TM these proteins constitute a pervasive framework for advancing or retarding glaucomatous damage.

In the third section, the mechanism of glaucoma elements as seen through the windows of the proteomics of adult prevalent: pseudoexfoliaiton, primary open angle, and pigmentary glaucoma are reviewed. Incriminating data on mutated/misfolded myocilin, (the first gene linked to glaucoma) and its contributors to compromised $\mathrm{AH}$ outflow and their repair pathways and their alternate roads to apoptosis are explored.

That said, it is worth keeping in mind that enhanced differential gene/protein expression levels of these (and other glaucoma genes) do not necessarily dictate a linear relationship to their functional outcomes. Thus, the concluding sections of this paper examine other dynamic vectors which characterize the somewhat hidden, non IOP elements of the disease: heat shock proteins, (with their immune clearance effect or their potential axonal cushioning effect), nitrous oxide donating moieties for increased $\mathrm{AH}$ outflow, glaucoma signal pathways, epigenetic and other modifiers for neuroprotection vs neurodegeneration in glaucoma. Such signal vectors as TGF beta, for example, can produce excess ECM, extracellular matrix protein, in the TM which can block AH outflow. But other transcription factors, such as MAP kinase can initiate a process for removal of aberrant proteins. Certain inflammatory factors can overload the clearance of misfolded proteins and other epigenetic chromatin modifiers can activate genes for alternate pathway clearance. The analysis of interactions of fortifying and debilitating vectors and their outcomes constitute the next platform for glaucoma therapy.

Thus, these vectors as well as aging, oxidative stress, protein misfolding, mitochondrial lysosome axis dysfunction/repair are all on a dynamic, wide stage of activity (for TM and RGC categories of glaucoma) with many actors in a comprehensive, ongoing dialogue of intracellular homeostasis, survival vs. glaucomatous damage and apoptosis.

\section{Outline}

POAG

GWAS

Genes Clinical Features

PXG Proteins \& Features

AH Proteins in POAG

Myocilin Protein Changes in Glaucoma

Pigmentary Glaucoma

POAG TM/RGC: 0x. Stress, 
>energy demand

on mitochondria,

Heat Shock Proteins:

Inflammation, immune,

autoimmune reaction;

$>$ damaged proteins $>$ Ubiquitin activity

Apoptosis

positive correlation:

mean visual field deviation

oxidative stress

Nitrous Oxide> AH outflow

\section{Glaucoma Signal Paths}

\section{Neuroprotection $v$ S}

\section{Neurodegeneration}

\section{Materials and Methods}

To obtain a broad spectrum of papers in genomics, proteomics, epigenetics and signal transduction pathways of glaucoma, each of these topics was named in association with glaucoma and searched in pub med and Google Scholar over the last two decades up to the year 2020. Papers that provided a systematic review with clear supporting evidence for associations of glaucoma to evidence-based mechanisms such as: genes from genome wide association studies, protein misfolding as a consequence of e.g myocilin mutations, the role of oxidative stress in mitochondrial/ cytochrome demise and apoptosis or E-3 ligase involvement in clearing dysfunctional protein were given greater weight as were their supporting reference papers. In this regard, papers that linked mechanistic findings with risk elements in glaucoma, such as visual field loss or vertical cup disc ratio were also weighted heavily in the initial selection.

\section{Results}

POAG Genome wide association studies, GWAS, ethnic genetic associations and genes associated with glaucoma clinical features

GWAS, have documented some 74 genomic loci that have been associated with POAG susceptibility. Some of these characterize ethnic specific risk factors as well as risk factors across diverse ancestry [8].

In the age groups, $40-80$ years, the global prevalence of POAG is $3.54 \%$. In those of African descent, it is even higher at $4.2 \%$. Worldwide in 2020 it was estimated to be a total of 64.3 million with glaucoma [5]. While elevated intraocular pressure, IOP, may or may not be associated with glaucoma, early on patients are often asymptomatic or only experience mild peripheral or central visual field disturbance, usually after silent optic nerve micro hemorrhage, ischemia, oxidative stress, inflammation, and immune reaction has caused some damage $[6,7]$.

Genome- wide association studies in POAG over the last decade have identified risk loci in European, Asian, Japanese and African populations [8]. Individuals of African ancestry have three to five times the POAG risk and worse visual field and disease progression than other populations [8-13]. Thus far, as is the case with Japanese populations, it is unclear if Asian study gene markers for the Japanese are able to be associated with other Japanese study loci, and, if loci from the African populations are compatible with studies of loci of African Americans [8,10-14]. However, Hispanic/ Latino populations, although much less explored in GWAS, have illustrated loci previously identified in GWAS of European or Asian populations in their Hispanic/Latino sample [8]. These and other genetic ethnic loci variances in different studies illustrate the genetic heterogeneity across populations. Other studies in glaucoma clinical features, such as intraocular pressure and vertical cup to disc ratio, have been examined with respect to genetic locus and potential POAG risk. Patients with these features and genetic loci may be higher risk and may require earlier intervention.

Unfortunately, thus far GWAS have not provided a specific overriding genetic mechanism for understanding glaucoma. However, certain POAG gene candidates have led to further investigation. For example, SIX6 (which is important in retina and optic nerve development) expressed abnormal gene variants and illustrated reduced protein elaboration in zebrafish in vivo assays, [1518]. With abnormal human homozygous SIX6 alleles vs normal homozygous alleles, the nerve fiber layer was thinner in the abnormal SIX6 homozygous population. The RGC are the primary target in glaucoma [31]. Moreover, a SIX6 gene variant showed increased expression of another POAG normal tension glaucoma locus, $C D K N 2 A$, in cell lines, and in human glaucoma with increased IOP causing senescence in retinal ganglion cells [19].

Clinical features of glaucoma have been correlated to GWAS POAG gene loci. FNDCB3 and FMNL2 have been associated with increased IOP $[20,21]$, and common loci variants $C D K N 2 B-A S$ and SIX6 were linked to increased vertical cup disc ratio [22].

PLEKHA7, HGF, FERMT2, and GLIS, four loci conferring risk to angle closure glaucoma, were from the group with increased intraocular pressure, suggesting that angle closure may contribute to elevated IOP even in patients ostensibly within the normotensive range $[8,20,23]$.

\section{Corneal thickness glaucoma GWAS study association}

A GWAS for central corneal thickness association with POAG found only one locus FNDC3B and surprisingly one central corneal thickness allele was found protective for POAG [24]. Another GWAS in over 25,000 European and Asian patients did not find 
any correlation between central corneal thickness and POAG or angle closure glaucoma $[4,25]$. This raises the question of whether the central cornea thickness-glaucoma criterium is in the same Table 1: Genome Wide Association Studies, Genes related to Glaucoma. category as intraocular pressure, vertical cup to disc ratio, and optic nerve change phenotypes, but rather another risk factor as yet to be understood on the genetic/proteomic landscape [8]. (Table 1)

\begin{tabular}{|c|c|}
\hline Genome Wide Assoc Genes & Glaucoma Outcome \\
\hline Six6 & Retinal Ganglion Cell, RGC/Optic Nerve Dev Early and later life [30] \\
\hline CDKN2A $/$ Six6 & RGC Pathogenesis in Glaucoma [32] \\
\hline FNDCB3, FMNL2 & Increased IOP [33] \\
\hline CDKN2B-AS and SIX6 & Increased vertical cup: disc ratio [35] \\
\hline PLEKHA7, HGF, FERMT2, and GLIS & Angle Closure Glaucoma [4,33,36] \\
\hline
\end{tabular}

Glaucoma: GWAS hints at systemic disease, angiogenesis pathways/tyrosine receptor kinase schlemm's canal IOP regulation; Glaucoma: Subacute bacterial inflammation (Toll Receptors) and Immune (Heat Shock Proteins, Toll

\section{Receptors in retinas with Glaucoma)}

Despite the fact that GWAS have not provided clear cut gene to disease understanding, they have provided candidate genes for further glaucoma study in animal models and human cell lines and glaucoma association with systemic disease, such as type 2 diabetes and cardiovascular disease [8,31].

In addition, not unlike the GWAS highlighting Complement Factor $\mathrm{H}$ polymorphisms in macular degeneration, and systemic disease associations [26-30], GWAS in glaucoma may have begun to elucidate loci linkages to (1) glaucoma phenotypes, (IOP and vertical cup to disc ratio) and (2) to systemic diseases, such as diabetes, myocardial infarction and stroke [8,28]. In the latter, for example, from both IOP GWAS studies, genes involved in angiogenesis and "vascular endothelial cell morphology" emerged with ANGPT1, ANGPT2 and VEGF-C gene variants. These genes are TEK (receptor tyrosine kinase) signal regulators for Schlemm's Canal modification of aqueous pressure. Mutations in TEK may cause primary congenital glaucoma [32]. Lesser alterations of the angiopoietin-TEK pathways may curtail efficient Schlemm's IOP regulation. TEK receptors are highly expressed in Schlemm's canal, [33]. In the mouse model, efficient maintenance of angiopoietinTEK signalling may be responsible for protective VEGF-C anterior chamber levels and normal intraocular pressure at the Schlemm's canal collector channels [34]. At this point, it is unclear if this VEGF-C IOP balancing/unbalancing may be in conjunction with TM dynamics in glaucoma, or, by itself a source of increased IOP.

Returning to the possible role of complement and immune response and inflammation in glaucoma (as in macular degeneration cited above) a recent study showed that glaucoma patients had higher bacterial oral counts compared to control subjects. Low dose bacterial lipopolysaccharide administration in glaucoma animal models developed enhanced axonal degeneration and neuronal cell loss. Microglial activation in the optic nerve and retina along with upregulation of TLR4 (Toll receptor 4) signaling and complement system, which was blocked by naloxone, suggested a bacterial/ infection, immune and possibly inflammatory role in glaucoma development [35].

In a related way, retinas from humans with glaucoma had parallel proteomic mass spectrometric and immunostaining for Toll Receptors 2,3,4. In line with upregulation of toll receptor signaling in the glaucoma samples, prominent expression increases in heat shock proteins were noted. Analysis of microglia and astrocytes in glaucoma vs control retinas also showed toll receptor expression increases. In vitro experiments after oxidative stress also showed heat shock protein increases in line with upregulation of glial Toll receptors and MHC Class II expression. Increased cytokine and $\mathrm{T}$ cell production were also linked to Toll Receptor upregulation [36]. These papers tie glaucomatous retinal tissue stress to upregulation of immune and inflammatory response [35,36].

Pseudoexfoliaiton glaucoma PXG, extracellular matrix, LOXYL1 gene, homocysteine, clusterin, misfolded protein, amyloid, hypoxia, chronic organic and brain disease association, life expectancy, hypoperfusion and elevated oxidative stress

Pseudoexfoliaiton syndrome (PXS), an aging disorder involving the extracellular matrix of the trabecular meshwork, ECM, (multiadhesive protein glycans, collagens, fibronectin, laminin, elastin, and others, secreted by TM cells for cell support, molecule migration, proliferation and differentiation) [37] is the most common risk factor for secondary glaucoma and a major cause of worldwide blindness. An estimated 60-70 million patients are affected [38-41].

A global sample of PXS identified new variants of LOXL1, a rare protective allele with greater cellular adhesion ability compared to the wild type and five new loci [42]. The protective LOXL1 in follow up histological investigation demonstrated decreased (1) elastic fiber formation, (2) tissue stiffness, and (3) cell adhesion in ocular tissues of patients with PXS [43].

LOXYL1 variation genes at the POAG locus have been associated with pseudoexfoliaiton glaucoma PXG. Of particular note, however, is that while the rare variant at LOXYL1 is protective, the five others nearby were only susceptibility loci. All five "LOXYL1 haplotypes detected by the resequencing effort showed reversal of genetic 
effect, their functional consequences remaining in doubt." [42]. Although LOXL1 participates in crosslinking of collagen and elastin in the extracellular matrix, LOXL1 has not been specifically shown to cause pseudoexfoliaiton. Another gene, CACNA1A, however, which codes for a subunit in the voltage-gated calcium channels, (which are widely expressed in the brain and ocular tissues), through calcium deposition on electron microscopy in pseudoexfoliaiton, may be linked to pseudoexfoliaiton $[43,44]$.

While the genomics of LOXL1 in pseudoexfoliaiton are as yet unclear, the role of lysyl oxidase, LOX, in the cell seems to be gaining greater understanding. Lysyl oxidase oxidizes the side chain peptide of lysine converting it to a semialdehyde which permits the covalent crosslinking of collagen chains and elastin. This stabilizes fibrous deposits and proteins in the ECM. Four LOXL proteins with varying similarity to LOX have been described. From this family of related proteins, a proLOX protein can emerge, which is activated to the enzyme lysyl oxidase, LOX.

LOX, in addition to overseeing crosslinking of collagen and elastin, plays a role in chemotactic responses, proliferation and shifts between normal and malignant phenotypes [45]. Thus, with the multifaceted and complex intracellular role of this gene/ protein family, the genomics await further clarification. This study, for example, demonstrated that some LOXL1 polymorphism alleles have different effects in different populations, with a given allele increasing pseudoexfoliation risk in certain populations but providing protection in others [46].

Increased levels of homocysteine in pseudoexfoliaiton patients in several studies may disrupt disulfide bonds of cysteine residues in extracellular matrix proteins. This homocysteine/ pseudoexfoliaiton may be relate to chronic folate deficiency which could disrupt the methione-homocysteine cycle and affect methylation of LOXYL1 and its expression [47].

Results remain mixed on the role of clusterin single nucleotide polymorphisms, SNPs. SNPs in some populations are positive and other populations negative for association to PXG. Clusterin, or apolipoprotein J, is secreted by almost all cell types and is named for its ability to cluster red blood cells. It is an extracellular matrix protein involved in reducing protein misfolding. Clusterin also binds amyloid and reduces amyloid formation in Alzheimer's disease [48-50]. In the eye, studies examining common clusterin protein variants for association with PXS have been inconsistent [50]. It is of interest, that the literature has a report of a 70-year-old with PXG and lattice corneal dystrophy with amyloid accumulation [51].

In addition, clusterin because of its in inhibition of oxidative stress, induced aggregation and precipitation of misfolded proteins, and regulation of complement, may mitigate heat shock protein elaboration and resist apoptosis [52].

However, Zenkel et al showed reduced immunoreactivity for clusterin in ocular tissues of PXG eyes [53]. Patients with focal segmental glomerulosclerosis also have reduced blood and urine levels of clusterin $[54,55]$.

Thus, there may be an initial beneficial clusterin level to reduce misfolded proteins in PXG, but its production is exhausted and its immunoreactivity in eye tissues diminishes. In other similar pathophysiologic situations such as drusen, corneal amyloid, arteriosclerotic plaques senile plaques in Alzheimer's disease, prominent initial immunoreactivity for clusterin is present. Continued oxidative stress and mitochondrial lysosome axis dysfunction may exhaust clusterin levels and reduce clearance of misfolded protein and increase tissue fibrosis [56,57].

Despite the well-known higher prevalence of pseudoexfoliaiton glaucoma in Scandinavia, a US cohort of Scandinavian ancestry was not found to be at risk for pseudoexfoliaiton glaucoma [58]. Environmental factors, such as number of days of solar exposure were suggested to play a role there. Others have linked lifetime residential latitude from the equator with increased odds of pseudoexfoliaiton glaucoma [59].

The variable risk of pseudoexfoliaiton glaucoma with some LOXL1 polymorphisms but not with others, as well as protective LOXL1 alleles in some populations, suggests that these alleles in different environments or under different stress factors, and even in different systemic diseases, (which have been associated with pseudoexfoliaiton glaucoma) may behave differently [44,60,61].

Chronic diseases of the brain, such as cerebral atrophy, chronic cerebral ischemia, and dementia were more common in PXG than POAG [62]. While some studies have illustrated risk of carotid, renal and cardiovascular disease in PXG, [63-67], others have not found linkage to cerebrovascular and cardiovascular disease [62]. A metaanalysis, however suggested the association of pseudoexfoliaiton syndrome with coronary artery disease, cerebrovascular disease and aortic aneurysm [64]. Despite the variability of pseudoexfoliaiton glaucoma with different systemic diseases, it would appear albeit paradoxically that multiple studies have not shown increased mortality in patients with pseudoexfoliaiton, $[63,66,67]$, and specifically a decrease in overall mortality and no difference in cardiovascular or cerebrovascular mortality [68]. Another study from Finland, interestingly, found increased life expectancy in pseudoexfoliaiton glaucoma patients compared to patients with POAG [69].

Poor pupillary dilation and loose zonules in pseudoexfoliaiton patients presents greater intraoperative complication risk with cataract surgery. Over half the late intraocular lens/capsule dislocations that occur more than three months after cataract surgery are related to pseudoexfoliaiton syndrome [70].

Corneas in patients with pseudoexfoliaiton regardless of the presence of glaucoma have decreased endothelial cell density and the central cornea is thin [71]. Decreased tear production and tear film stability has also been observed in pseudoexfoliaiton syndrome 
[70].

It is possible that some of the above findings in patients with pseudoexfoliaiton syndrome may relate to hypoxia, oxidative stress and ischemia. On electron microscopy, progressive iris vasculature degeneration from adventitia to endothelium was noted in the setting of hypoxia in pseudoexfoliaiton patients not seen in controls [72]. Subfoveal choroidal thinning was more recently noted in pseudoexfoliaiton eyes perhaps secondary to choroidal hypoperfusion secondary to impaired carotid flow $[73,74]$. Color Doppler imaging of the ophthalmic artery in pseudoexfoliaiton glaucoma patients identified increased vascular resistance [75]. Oxidative stress and inflammation have been cited in patients with early pseudoexfoliaiton syndrome. Elevated oxidative stress with decreased antioxidant capacity was found in $\mathrm{AH}$ of pseudoexfoliaiton patients compared to controls [76]. TNF-alpha, IL-6, and IL-17 were also reported increased in AH of early stage pseudoexfoliaiton glaucoma patients compared to controls [77].

Prominent Aqueous Humor Proteomic Changes in POAG, elevated:

1) immune globulin and alpha trypsin inhibitor (immune and inflammatory responses),

2) lipid metabolism (protein-lipid, lysosomal degradation transport, clearance),

3) ATP dependent chromatin remodelling (epigenetic energy dependent methylation/acetylation, balancing, re- balancing),

4) glycoproteins (associated with ECM function and remodelling)

5) isocitrate dehydrogenase (NAD mitochondrial balance)

In fact, in line with higher inflammatory and immune response in the $\mathrm{AH}$ of PXG patients, using liquid chromatography-mass spectrometry informatics, 33 distinct proteins from the aqueous humor of POAG glaucoma patients were identified. They were characterized by such diverse cell functions such as signalling, glycosylation, immune response, molecular transport and lipid metabolism [78]. An increasing trend in the odds ratios of having POAG was noted with increased levels of these proteins in the aqueous humor, $\mathrm{AH}$. The four highest protein levels in $\mathrm{AH}$ proteins were found in Ig $\mathrm{j}$ chain $\mathrm{C}$ region:13.56 fold (immunity related), inter-a-trypsin inhibitor heavy chain 4: 4.10 fold (protease inhibitor, also involved in immunity and inflammation), apolipoprotein C III: 3.36 fold (triglyceride metabolism), and isocitrate dehydrogenase (NAD) (mitochondrial enzyme for energy balance) 3.1 fold [78].

To understand associations of the 33 significantly altered proteins in POAG, bioinformatics (canonical pathways using ingenuity pathway analysis) in POAG were compared to controls.

Thus, the proteins in the POAG group were highly involved in immune, inflammatory response, lipid metabolism, (likely lipid transport in and out of lysosomes), extracellular space activities (as in the aqueous humor), repressor element silencing transcription factor (REST), and ATP dependent chromatin remodeler transcription factor [78].

Fifteen of the thirty-three elevated AH proteins in POAG belong to the glycoprotein and glycosaminoglycan category. One of the key components of the POAG juxtacanalicular TM tissue is accumulation of ECM fibrillary elements associated with glycoproteins $[78,79]$. These TM proteomic distinctions will be reviewed in several of the later result topics such as myocilin/ misfolded protein, oxidative stress, and pigmentary dispersion syndrome and signal pathways in glaucoma.

MYOC TM Endoplasmic Reticulum Dynamics: Mutations/ Misfolded Proteins trigger Autophagy; Myocilin and IOP Increase after Oxidative Stress; overload misfolded protein results in amyloid myocilin accumulation and TM thickening and pre apoptotic signalling; secondary autophagic pathway activated through Unfolded Protein Response for misfolded protein overload; sustained elevated IOP (Intraocular Pressure) results in NFKB/ IL1 and variable Metalloproteinase, MMP, IOP responses, which can relax TM and lower IOP, or increase TIMP3, inhibit MMP and raise IOP; and Dexamethasone raises fibronectins, tightens ECM and raises IOP; Antioxidants, higher Temperatures: protective: less myocilin misfolding, lower IOP

MYOC gene, which codes for myocilin protein (highly expressed in the TM), is likely inherited as a familial trait, and may be helped by familial genetic assessment and counselling. It has been associated with a more aggressive, juvenile onset open angle glaucoma (accounting for 10\%) and adult onset open angle glaucoma (accounting for 2-4\%). Mutations in myoc-OLF, olfactomedin domain, (protein structured like five bladed beta-propellers, beta protein sheets around a central axis), are responsible for aberrant myocilin protein and enzyme interactions and thought to be associated with the development of glaucoma $[80,81]$. They have a sodium and calcium ion and glycerol molecule within a central hydrophilic cavity that is accessible after movements of surface loop residues [81].

That said, it is unclear if overexpression of mutant myocilin is the actual source of development of glaucoma. For example, Pro370Leu is one of the most severe glaucoma phenotypes, which is tied to TM cell mitochondrial dysfunction leading to apoptosis $[80,82]$. However, Gln368Stop, which is the most common myocilin mutation, has low penetrance for glaucoma. So, from the genetic standpoint, while mutant associations do exist, it is unclear whether various mutant allele types determine gain or loss of function with respect to the pathogenic glaucoma mechanism [80,82-85].

Recent studies [86-88] have indicated that the lack of sufficient myocilin is not the source of glaucoma, but that it is dependent on the over expression of mutant/misfolded myocilin. It is the aggregate of the misfolded proteins in the endoplasmic reticulum of the TM 
cells which produces stress in the endoplasmic reticulum as well as increased oxidative stress which leads to excess reactive oxygen species, reduction/oxidation imbalance, decreased antioxidative enzymes and to apoptosis [89,91-93]. Repeat misfolded protein accumulation without clearance of degraded products leads to amyloid containing myocilin [94]. This adds to the reduced clearance in glaucoma and with the greater protein aggregate raises IOP and further damages outflow channels [94].

Interestingly, co-aggregation of Grp94, glucose regulated protein 94, with mutant/misfolded myocilin OLF protein while resulting in greater endoplasmic reticulum deposits also enhances coprecipitation of myocilin-OLF $[94,95,97]$ and has been suggested as an anti-glaucoma therapy to clear mutant/misfolded myocilin $[94,95,97]$. Alternatively, using a secondary autophagic pathway through 4-Br-BnIm (which is a Grp94 inhibitor), 4-Br-BnIm clears aggregated myocilin and alleviates myocilin TM toxicity [98]. Thus, with TM endoplasmic reticulum congestion from excess mutant misfolded myocilin aggregates, co-precipitators, like Grp94, as well as two autophagy pathways can help alleviate the toxic misfolded protein accumulation.

Apparently under normal conditions, myocilin misfolded aggregates are cleared by ubiquitin-proteasome lysosomal pathways. However, mutated or misfolded myocilin, after dysfunction of the primary proteasomal pathway, induce a secondary autophagic pathway (through activated unfolded protein response UPR) in an endeavour to protect TM cells. So, while Grp94 may act as a co-aggregator of myocilin misfolded protein and reduce their contribution to glaucoma, it may also induce the alternate clearance autophagy pathway. [95,96,99,100] Grp94 inhibitors prevent Grp94 from aggregating with myocilin mutants, but also result in initiation of the secondary autophagic pathway leading to mutant myocilin clearance [96].

The TM in patients with glaucoma with myocilin mutations is thicker than that of patients without myocilin mutations [101]. Misfolded myocilin aggregates in the ER of TM cells not only illustrate morphological changes but also lead to apoptosis [90,101,102]. The mutant misfolded myocilin aggregates in the ER promote increased reactive oxygen species, $[89,95,96,102]$ induce TM ER dysfunction, apoptosis, and increased IOP [86-87,105-107]. Reactive oxygen species that are then in the aqueous humor plus those from the TM cause additional protein misfolding [93]. So, it becomes a vicious cycle of cellular and aqueous reactive oxygen species increasing mutant myocilin misfolding which renders cells more sensitive to oxidative stress [93-94]. Mutant myocilin inhibits antioxidant enzymes, such as paraoxonease 2 , which with less oxidative stress efficiently inhibits endoplasmic stress-induced apoptosis [94]. Also, with greater oxidative stress, aggregated misfolded myocilin initiates the unfolded protein response, UPR, which (as mentioned above activates the alternate autophagy response to help protect TM cells), [107,108], reduce protein misfolding and degrades misfolded proteins [108-109]. If ER stress is not checked, then UPR induces apoptosis [89-90]. The aggregate myocilin misfolded proteins after high ER and oxidative stress aggregate amyloid to the myocilin misfolded products resulting in more severe glaucoma $[89,94]$. Thus, in addition, the excess aggregates are not readily cleared by the primary proteasomal pathway and require Grp94 inhibition with 4-Br-BnIm to reduce misfolded myocilin protein pile-up and TM toxicity $[93,94,97]$ via the secondary autophagic pathway $[95,99,100]$.

In line with the activation of IL-1/NFKB inflammatory stress response in high tension glaucoma [110], other proinflammatory mediators such as IL1 beta and mutant myocilin aggregate within the TM cells, activate the NFKB inflammatory pathway and raise IOP. Extracellular mutant myocilin, (outside the TM cells), does not activate NFKB signaling pathway [111].

The flip side to this is that IL-1 by stimulating matrix metalloproteinase MMP [111] and inhibiting apoptosis caused by oxidative stress through NFKB, [110] may reduce IOP. However, both IOP and oxidative stress are associated with the aggregation of misfolded mutant myocilins [86]. Interestingly, the aggregation of different misfolded mutant myocilins may upregulate IL-1 to different levels. Gln368Stop increased IL-1 tenfold in TM cells while those TM cells harboring Try437His induced IL-1 only sixfold. Gln368Stop, with the higher anti-inflammatory effect of IL1, had a greater IOP reduction than Try437His in the short term. Gln368Stop is the most prevalent mutation but exhibits less elevated IOP glaucoma phenotype $[80,111]$.

Matrix metalloproteinase 2, MMP2, which is abundant in TM [112], is involved in extracellular matrix breakdown [113] and facilitates the outflow of aqueous humor. However, myocilin mutations, or MYOC null, can increase TIMP3, tissue inhibitor of metalloproteinase, which can inhibit MMP2 and cause POAG [114]. Lowering MMP2 can reduce the breakdown of extracellular matrix altering TM function leading to elevated IOP $[80,93,116]$

In addition to metalloproteins, inflammatory cytokines, misfolded/ mutant myocilin, amyloid, clusterin, reactive oxygen species, antioxidant enzymes, primary and secondary proteasome/ lysosome proteins (all interacting in the dynamic of the TM/ aqueous humor outflow system), fibronectin [115] and flotillin-1 [116] have also been identified as interacting with myocilin. The five bladed protein propellers of myocilin-OLF is an accepted bioenergetic platform for protein-protein interactions $[80,81]$.

Mice with myocilin-Tyr437His which is less of an antiinflammatory inducer of IL-1, have a higher fibronectin and CHOP (a TM ER stress marker) protein expressions [115]. Mutant myocilins in another study [110] increased CHOP and Grp78 in TM.

Of note is that following dexamethasone anterior chamber treatment [117] myocilin, fibronectin, CHOP and Grp78 levels were increased. Treatment with sodium 4-phenylbutyrate decreased the 
dexamethasone induced increased IOP and fibronectin aggregation in TM cells [117]. The failure of the TM to control ER stress from misfolded/mutant myocilin results in increased CHOP which leads to apoptosis and increased IOP in TM cells [109].

Flotilin-1 a structural protein of the plasma membrane, which is rich in cholesterol and sphingolipids and involved in moving protein molecules from the cell surface to the interior, (like a raft), using endocytosis, also interacts with myocilin. Myocilin mutations, however, including Tyr437His and Gly364Val fail to interact with Flotilin-1 [117]. The absence of myocilin mutant interaction with flotillin-1, because of its centrality to aqueous humor protein dynamics may be another step-in protein mismanagement and glaucoma progression [117].

A severe myocilin glaucoma mutant, Pro370Leu, co-expresses hevin a protein involved in assembly of extracellular matrix [118]. The myocilin mutation causes intracellular accumulation of hevin and reduces its secretion compromising the production of extracellular matrix [119]. This may represent yet an additional

Table 2: Short List of Myocilin Proteomics and Glaucoma.

\begin{tabular}{|c|c|}
\hline Protein & Role in Glaucoma \\
\hline Myocilin & ? role mutated vs misfolded; [86-95] \\
\hline Myocilin: Mutated, misfolded, aggregated & $\begin{array}{c}\text { >ECM thickness, > IOP ref } 101 \text { Inhibits Matrix Metalloproteinase, increases Tissue Inhibi- } \\
\text { tors of Matrix Metalloproteinase: tightens ECM, > IOP; [227,229] }\end{array}$ \\
\hline ? Combined with amyloid, [87] & ? With clusterin higher concentration < amyloid; \\
\hline Amyloid [94] & ? With clusterin lower concentration >amyloid \\
\hline ? With clusterin [47-49] & With amyloid or CHOP > protein folding, \\
\hline With CHOP $[108,109]$ & $\begin{aligned} \text { >aggregates and } & >\text { resistance to outflow CHOP a vital oxidative stress, protein misfolding } \\
& \text { signal generator and can trigger apoptosis }[109,110]\end{aligned}$ \\
\hline $\operatorname{Grp}[94,98]$ & $\begin{array}{c}\text { Clears myocilin aggregates, } \\
\text { Opens } 2^{\text {nd }} \text { autophagic clearance pathway }\end{array}$ \\
\hline Paraoxonease [94] & antioxidant in oxidative stress \\
\hline Unfolded protein response & $\begin{array}{l}\text { Unfolds misfolded proteins; Activates the second autophagic pathway; but excess misfold- } \\
\text { ed proteins and oxidative stress can trigger apoptosis }\end{array}$ \\
\hline IL-1 emanating from some misfolded myocilin mutants & $\begin{array}{c}\text { Inflammatory Activity, }>\text { NFKB and }>\text { IOP, but also get }>\text { matrix metalloproteinase with }<\text { risk } \\
\text { of apoptosis }[227,229]\end{array}$ \\
\hline $\begin{array}{l}\text { but some myocilin mutants can lower IOP, e.g. wild type } \\
\text { MYOC activation can inhibit IL-1/NFKB, }[104,111]\end{array}$ & < IOP; stimulates Matrix Metalloproteinase and can reduce the risk of apoptosis \\
\hline Dexamethasone, [110,113] & Fibronectin, >ECM deposits and tightening, >IOP \\
\hline$<30$ degrees $\mathrm{C},[102]$ & Myocilin misfolding \\
\hline
\end{tabular}

Pigmentary Dispersion Syndrome (PDS)/Pigmentary Glaucoma (PG), differences from PXG, TM pigment deposits instead of punctate deposits of PXG; phagocytic pigment stress alters TM/ ECM clearance resulting in dysfunctional TM, adhesions, and cell death; premelanosome protein, essential for melanosome melanin, synthesis, storage and transport, had structural changes to pseudo melanosomes with altered amyloid fibril formation and significant ocular pigmentation defects; complex additional pigment protein interactions linked to melanin toxicity, immune attempts at clearance, step in the development of glaucoma, albeit not through the TGF beta pathway, but rather through cell adhesion to fibronectin or myocilin like binding through its homologous C-terminal domain to modulate ECM proteins [119].

Returning to the myoc-OLF protein structure, additional evidence has pointed to the relationship of pathogenic myocilin mutation aggregation and thermal instability $[89,102]$. The largest number of mutations occur in core beta-sheet belts (40\%), loop B-10/C-11 and cation pi (33\%). These misfolded mutants show a difference in melting temperature which is about two degrees $C$ lower than wild type myocilin-OLF and resulted in more intracellular insoluble aggregates and early onset, more severe glaucoma [80,102,120-122]. Trimethyl N-oxide and sarcosine hold the number of myocilin melting temperature mutations to near the wild -type myocilin levels [123]. 30 degrees $\mathrm{C}$ is known to facilitate proper protein folding $[122,124]$. Thus, lower temperatures or temperature sensitivity (and possibly their greater oxidative stress/ energy deficient sources) may be another assailable area in proteomic misfolding and glaucoma development [80]. (Table 2) 
do not correlate with glaucoma/corneal thickness differences $[131,132]$. Unlike the patients with pseudoexfoliaiton syndrome who have punctate deposits of material in the TM, PDS patients have diffuse and uniformly dense pigmented TM [133]. Histologic exam showed that TM and corneal cells phagocytize the excess pigment granules but are then subject to phagocytic stress which compromises TM ECM structure and causes adhesions. TM cells become dysfunctional, exhibit local and then more extensive necrosis and death [134]. Aqueous humor outflow is reduced and PDS is converted to PG $[135,136]$. The amount of TM pigmentation corresponds to the severity of the optic neuropathy in PG patients $[137,138]$. However, the defect in retinal pigment epithelial cells degranulating is unclear.

PG represents about $1.25 \%$ of the glaucoma cases and since its early age of onset, it is the most common cause of non-traumatic glaucoma in young adults. Although not as yet replicated, analysis of four pedigrees of three generations, with Irish or mixed Western European ancestry affected by PDS/PG showed an autosomal dominant transmission, which mapped to human chromosome (7q35-q36) [138]. Other potential genes include, human endothelial nitric oxide synthase which maintains vascular tone and may contribute to iris structural defects [139-141]. MYOC and lysyl oxidase genes have had suggested limited association with PDS/ PG glaucoma, but because of small number of associated variants of the former and small sample size of the latter [142-147] causal relationship is lacking. Known anterior segment developmental control genes such as PAX6, [148], FOXC1 [149] and PITX2 [150] are not associated with PDS/PG but rather with anterior segment dysgenesis, FOXC1 and PITX2, and with microphthalmia, PAX6, [151].

Missense mutations in Tryp1, alleles (which would otherwise produce tyrosinase and normal melanin pigment) has produced iris atrophy in mouse strains. Alteration of cysteine residues in Tryp1 alleles also causes the release of toxic melanin intermediates from melanosomes, which result in melanocyte death. Yet other genetic mouse mutations, such as in Dct, has also been associated with PDS through the tyrosinase complex and may produce melanosome dysfunction and cytotoxic melanin synthesis intermediates [152156]. The human homologue OCA2, a melanosome regulator of $\mathrm{pH}$, has been linked to oculocutaneous albinism type 2, and has been associated with iris color [157-161].

Some recent work suggested a strong possible protein driver of PG, defective processing of PMEL, (premelanosome protein identified in humans with PDS/PS using whole exome sequencing of the two independent pedigrees). PMEL, essential for melanosome melanin, synthesis, storage and transport, had structural changes to pseudo melanosomes with altered amyloid fibril formation in five of nine gene variants. CRISPR introduction of the 11-base pair deletions to homologous PMEL in zebrafish caused significant ocular pigmentation defects and enlarged anterior segments. This suggested that variants in human PMEL are responsible for PDS/ PG [163].

DBA/2 mice, which have iris transillumination defects [161, 162], have other gene defects that have been implicated in pigment dispersion phenotypes, some of which tie into immunosurveillance, trafficking, and melanocytic detoxification. Gpnumb, (glycoprotein nonmetastatic melanoma protein) which is involved in containing melanosome cytotoxic melanin synthesis intermediates, has additional neuronal and immune cell adhesion functions. Lyst is another protein traffic monitor but at the lysosome interface for early melanosome variants. The latter can cause Chediak-Higashi syndrome, (childhood immune disorder with reduced skin and ocular pigment, immune deficiency with frequent infections and easy bruising and bleeding). However, iris pigment epithelial dysfunction, whether mediated by: (1) release of synthesis, transport, or storage inept premelanosome derivatives, cytotoxic melanosome derivatives, (2) oxidative stress with excess melanogenesis over and above routine iris pigment maintenance, (3) inappropriate immune monitoring and clearance of excess melanin variants (3) cytotoxic melanin pigment metabolic derivatives, (4) inappropriate melanosome/mitochondrial interfacing and trafficking, and (5) melanosome apoptosis or necrosis from inflammatory mediators [164-168] has left these oxidative stress/metabolic/inflammation and immune research topics open for further investigation.

In the realm of linking signal transduction pathways, Myo5A for myosin, protein kinase $\mathrm{C}$, $\mathrm{PKC}$, for signaling, and transcription factor zinc finger ZLbtb20 have been associated with iris transillumination defects [162]. The association of Myo5a and protein kinase $c$ has been through intercellular melanocyte movement [165-167] or melanocyte dendrite formation [167]. Interestingly, suppression of Rho $A$, a target gene of micro RNA340 and promoter of actin, appears to regulate UVB induced dendrite formation and melanosome transport as well [169].

$D B A / 2 J$ mice develop a pigment dispersing iris disease that leads to elevated IOP and RGC loss. The mutant alleles of two genes, Gpnumb and Tryp1, respectively cause two components of iris disease, iris pigment dispersion and iris stromal atrophy [170]. The phenotype for iris pigment dispersion is similar to the pigment dispersion syndrome seen in humans $[170,171]$. By adding bone marrow of $D B A / 2 J-G p n m b+$ mice to $D B A / 2 J-G p n m b-$ mice, the iris disease and subsequent IOP rise can be mitigated [172,173]. Bone marrow derived lineages of standard DBA/J2 mice may have different immune inflammatory responses than the $D B A / J 2+$ mice. While adaptive $\mathrm{T}$ and $\mathrm{B}$ cell mediated components have been ruled out [172] other inflammatory immune or innate genetic immune responses may be at work $[172,174]$.

On the other hand, if the structural iris concavity, prevalence of myopia, and excess iridozonular contact which removes pigmented cells from the iris pigment epithelium via mechanical rubbing in patients is the etiology, then midperipheral and radial iris 
transillumination defects may correlate to just mechanical forces [128,175-178].

That said, if the mechanical theory is a root cause of the glaucoma, (and there is a type of reverse pupillary block with iris concavity and subsequent abnormal iridozonular rubbing with pigment shedding), one might argue that laser peripheral iridotomy which would flatten the iris and avoid the chafing would retard the glaucoma progression. However, a large database review of laser peripheral iridotomy did not report any reduction in visual field loss or glaucoma progression [179-181].

Thus, the exact sequence of PDS phenotype pathophysiology is not yet clear and the genetic and proteomic markers from the models also need better correlation.

POAG genes: lipid, cholesterol levels: risk factors; Mitochondrial support gene regulation; Retinal Oxidative Stress, Misfolded Proteins, Mitochondrial/ Lysosome Pathway Clearance/ Dysfunction, Retinal Heat Shock Proteins/Antibodies, autoantibodies (in Glaucoma); Excess Inflammation and Immune Reaction,

\section{Apoptosis}

Oxidative stress related to different levels of cholesterol, lipid [8], glycoprotein products as well as mutations in genes for dysfunctional protein removal lead to endoplasmic reticulum protein misfolding, inadequate mitochondrial energy production, lysosomal dysfunction and toxic intracellular accumulation [182].

Genes ABCA1, CAV1, DGKG, and ARHGEF12, which are POAG and intraocular pressure loci, are involved in lipid metabolism [183]. High serum cholesterol has been associated with the risk of POAG, while statin use may be protective $[184,185]$.

In a similar fashion, but different metabolic side of the picture, TXNRD2, thioredoxin 2, which regulates mitochondrial metabolism, and helps reduce oxidative stress, (as well as four other mitochondrial loci) have been associated both with POAG and IOP loci [186]. These lipid and primary metabolic/energy linkages may portend future approaches to glaucoma [8].

Elevated auto antibody levels against heat shock proteins (HSP) 27 and 60 were found in human donor retinae from normal and high-pressure glaucoma patients [187]. The heat shock proteins are highly conserved and ubiquitously expressed in response to metabolic, oxidative and thermal stress. They endeavor to prevent protein denaturation and aggregation and assist in refolding misfolded protein [188]. Immunogenic peptides either extracellularly or intracellularly and bound by the HSP are taken into lysosomes or proteasomes for degradation $[189,190]$. Thus, the effects of heavy oxidative stress result in dysfunctional mitochondrial proteins and other misfolded proteins which invoke the assistance of HSP which endeavor to help re-fold misfolded proteins and provide anti-apoptotic support as they arrange misfolded protein clearance either through the lysosome apparatus or immune aggregation $[7,189,190]$.
Lysosomes fuse with autophagosomes to deliver the hydrolases that degrade the misfolded protein. mTORC 1 signaling regulates lysosomal function. Under nutrient rich conditions, mTORC1 phosphorylates transcription factors like MITF, Microphthalmiaassociated transcription factor, a master gene regulator for melanocytes, cell cycle progression, and differentiation. MITF then initiates timely cytosolic chaperone maintenance which inhibits autophagy misfolded protein clearance. In the absence of nutrients or under stress, autophagy inhibition is relaxed leading to lysosomal and autophagy gene induction $[189,190]$. Thus, the HSP are facilitators to misfolded protein degradation as well as to immune antibody reactions, protective and autoimmune [7].

Some of these protein antigens, however, are transported to the endoplasmic reticulum where they are loaded to the major histocompatibility complex, MHC, and transported to the cell membrane to present to the $\mathrm{T}$ cell as either foreign or endogenous which then leads to protective immune reaction [191,192]. However, in addition to the antigens triggering antibody reactions, some HSP proteins themselves trigger autoantibodies which can result in damage $[7,193,194]$. In rheumatoid arthritis patients, for example, cross reactive $\mathrm{T}$ cells have produced autoantibodies to self HSP as well as other antigens. This two-sided immune exuberance produces an inflammatory reaction, which may or may not be balanced by immunosuppressive activity of other HSP or yet other anti-inflammatory pathways [194,195-197]. Trauma, excess heat, chemical attacks, radiation, hypoxia and oxidative stress may incite or contribute to the HSP immune or inflammatory response. The plasticity of HSP-mediated immunity (i.e. priming T cells for various HSP mediated immunity, cytokine Th2, Th2 and Th 17, and/or T cell regulatory by itself) varies with the ability of HSPs to engage local antigen presenting cells, through cell surface receptors, thereby stimulating diverse costimulatory signals [194].

Wax and his group 20 years ago showed higher antibody levels against HSPs (alpha and alpha B crystallin, HSP27 and HSP60) in normotensive and high-pressure glaucoma groups than controls. Similar elevated autoantibodies to HSP in normotensive and highpressure glaucoma patients vs controls were made in U.S and Japanese populations [198-200]

In a rat model, intraperitoneal HSP immunization produced IOP related retinal ganglion cell density reduction after 28 days [201]. In later rat model studies, intravitreal HSP application also led to an IOP independent loss of retinal ganglion and amacrine cells after 21 days [202]. Others, [204,205] have demonstrated immunolocalization of HSP in normal and laser induced glaucoma monkey eyes as well as rat retinal ganglion and glial cells in rat glaucoma.

However, the exact role of HSP in glaucoma is unclear and may be situationally dependent [7]. As cytoplasmic chaperones, HSPs contribute to refolding of misfolded and denatured proteins. HSP27, HSP70 and the small heat shock proteins are known 
regulators of apoptosis, [205,206] stress induced apoptosis, [207], bind pro-apoptotic protein activators, [208], oxidative stress neuro-protectors in RPE environment, [209], inhibit autoproteolytic maturation, caspase 3 activation, [210], and axonal degeneration [211]. On the flip side, because of their role in misfolded protein, degenerative protein aggregates, ubiquitination, antibody generating capacity as well as autoantibodies and proinflammatory T cells and cytokines, HSP can cause inflammation and autoimmune degeneration [211-217].

POAG TM oxidative stress: (unable to sustain AH outflow); HSP, Juxtacanalicular resistance, ECM products and thickening; Endothelial cell/ mitochondrial energy demand, damage to mitochondria and ubiquitin pathway for damaged protein removal to proteasomes; greater oxidative stress and inflammation, apoptosis; progressive visual field changes with oxidative stress

Oxidative stress by heat shock (44 degrees $\mathrm{C}$ for 15 minutes or hydrogen peroxide, 200 micromole for 1 hour) to human and monkey fresh and cultured trabecular meshwork TM resulted in significant increase in alpha beta-crystallin HSP with a peak after four hours expressed predominantly in the cribriform area (juxtacanalicular, JCT, region near Schlemm's Canal), the area of greatest resistance to aqueous humor $\mathrm{AH}$ outflow [218].

Over a longer time period due to imbalance between $\mathrm{AH}$ production and outflow [219-220] the main risk factor in POAG progression, the TM undergoes chronic inflammation and tissue remodelling [221,222]. Protracted oxidative stress produces TM and endothelial cell mitochondrial damage leading to neural degeneration and apoptosis [223,224]. The ECM develops increased collagen, fibronectin, and elastin with unusual myofibroblast development with thickening of trabecular sheets [221,225-229].

The AH of 14 patients with POAG, and not in controls, expressed elevated protein levels of ELAM, (endothelial leukocyte cell adhesion molecule expressed only on endothelial cells activated by cytokines, involved in inflammation), apolipoprotein $\mathrm{B}$ and $\mathrm{E}$ (for cholesterol delivery to cells.), three heat shock proteins, five muscle related proteins, a ubiquitin (for removal of stress damaged proteins), and three signal transduction proteins. These proteins may play a role as biomarkers for POAG [230] and form the core of protein mechanics in evolving glaucoma.

In later work, to better understand the TM ECM metabolism, fibrosis, and angiogenesis in 40 glaucoma patients, these investigators examined digital spectrophotometry/chip-based array AH protein profile expression vs controls. The inflammatory cytokines, particularly IL10, 6, 5, and 7 were all over tenfold increased. TNF alpha (a pro-inflammatory cytokine) was 2.48fold increased; TNFR was increased over four-fold. MMP2 (matrix metallopeptidase 2, produced in cells throughout the body and becomes part of the extracellular matrix, which is an intricate lattice of proteins and other molecules that forms in the spaces between cells) was 3.18 increased; VCAM1, (vascular adhesion protein- a cell adhesion molecule), MIP (macrophage inflammatory protein), 1delta, and MIP1alpha were all increased greater than fivefold. Thus, the large anti-inflammatory response levels and the moderately elevated metalloproteinase level suggest steady profibrosis increment under the umbrella of heavy anti-inflammatory cover. The POAG ECM change over time may be excessive and/or aberrant and necessitate an anti-inflammatory arsenal of a large magnitude to maintain a consistent aqueous outflow, in the face of incremental resistance [231].

In 202 Japanese NTG and POAG patients, blood analysis was performed for oxidative stress levels and compared to controls. Lipid peroxides, ferric reducing activity and thiol antioxidant activity were measured using a free radical analyzer and statistically compared with mean deviation of visual field. Univariate and multivariate analysis suggested a positive correlation between mean visual field deviation and biologic antioxidant potential. Use of more medication for glaucoma and POAG (vs NTG) were also associated with worse visual field progression [232].

\section{TM, JCT, ECM in normal, glaucoma, glucocorticoids}

In normal human eyes, using specific antibody immune electron microscopic determination, basement membrane like material in the JCT was identified as mostly collagen type IV, laminin and fibronectin. Elastin, however, was found in the central area of sheath related plaques. Fibronectin, fibrillin-1, MAGP-1, (microfibril associated glycoprotein), decorin (a collagen protein found in human skin) and type VI collagen were seen in clusters of the banded material in the sheath surrounding the core. Myocilin associated mainly with sheath material such as fibronectin and fibrillin [233-237].

In patients with POAG, excessive abnormal accumulation of sheath derived plaques has been shown on EM, immune and histologic studies. Of particular interest is the association of myocilin with microfibrils, which may have a role in the evolution of sheath density, plaque development and aqueous outflow reduction, (see figure 5 in ref 233 paper) [233].

However, glaucomatous TM characteristically show increased rigidity and stiffness with the formation of cross-linked actin networks with greater aqueous outflow resistance.

An increase in fibrillar content in JCT ECM is prominent in POAG and steroid induced glaucoma [238]. Other studies have detected increased calcification of the TM, which may increase TM stiffness and increase outflow resistance in glaucomatous tissue [239]. 


\section{Nitrous Oxide Donating Moieties for TM increased AH outflow}

Therapeutic approaches to lowering IOP include: (1) reduction of aqueous production, (beta blockers, carbonic anhydrase inhibitors, and alpha agonists); (2) increasing uveoscleral outflow, (extracellular matrix remodeling, prostaglandin agonists); (3) contracting the ciliary muscle, (opening spaces in the TM), pilocarpine); (4), increasing trabecular outflow, nitric oxide, (NO donating moiety).

Nitrous oxide plays many roles in the body. It has anti-platelet function in type 2 diabetics, assists smooth muscle relaxation (through vasodilation) in cardiovascular, urogenital, gastrointestinal and respiratory settings, as well as pro/anti-inflammatory and pro/ anti-microbial roles in high/ low NO venues.

iNOS isoforms of NO (from inducible NO genes) is the predominant form in TM and eNOS (endothelial) is the major isoform expressed by SC cells [240-248]. NCX434, a NO donating triamcinolone acetate has been used to improve retinal vascular blood flow and improve optic nerve oxygenation in the cynomolgus monkey model of glaucoma $[249,250]$.

Latanoprostene bunod, latanoprost combined with a NO donating moiety has been effective in lowering IOP even in the early morning hours when the IOP spike is common and affects the TM and SC to achieve additional IOP reduction vs. latanoprost alone, and was more effective by $1-2 \mathrm{~mm} \mathrm{Hg}$ than both latanoprost and timolol over a 52-week period [251-253].

By inhibiting Rho kinase, a protein kinase which helps modify cell shape, size and adhesion by altering actin cytoskeleton, TM cells allow increased outflow of $\mathrm{AH}$.

Netarsudil, the active compound in Rhopressa, FDA approved in 2017, uses rho kinase inhibitor which increases aqueous outflow and a norepinephrine transport inhibitor which by constriction of vessels to the eye reduces blood flow to the ciliary processes and aqueous production as well [254].

Signal Pathways in Glaucoma, TM: TGF beta, Rho Kinase, ECM contractile morphology, rigidity, MAP Kinase, E3ubiquitin ligase protein clearance; BDNF neuroprotection Signal Pathways in Glaucoma

In a normal setting, if threats of oxidative stress, hypoxia, trauma, mechanical forces result in inflammation and immune reaction, then transcription factors, (powerful nuclear genes) and histone modification of other protective genes establish defense plans, that are responsible for an efficient measured response. In glaucoma, the overactive TGF-beta signal pathway, which is usually helpful in healing, produces excess extracellular matrix protein deposition in the TM and blocks outflow of AH. Treatment of human TM cells with TGF-beta 2 upregulates Plasminogen activator inhibitor and secretion of fibronectin which increases extracellular matrix production. [7,256] TGF-beta2 induced ECM deposition and reduced outflow facility of aqueous humor by $27 \%$ in cultured human anterior segments [257].

TGF-beta2 is responsible for signaling differentiation, proliferation, chemotaxis and fibrosis. In healthy eyes TGF-beta2 helps corneal healing. In glaucoma TGF-beta2 causes increased extracellular matrix proteins in the TM cells resulting in fibrosis and blocked outflow of AH. Glaucoma patients have increased levels of TGF-beta2 in AH compared with normal [258,259].

TGF-beta increases ECM through the traditional Smad pathway (which conveys cell surface signals to intracellular mediators known as Smads, serine/threonine kinase receptors, causing their transfer from the cytoplasm to the nucleus, where they function to control gene expression), as well as the Mitogen-Activated Protein (MAP) kinase and Rho kinase pathways [7]. MAP kinase pathway leads to MAP ERK kinase resulting in increased ECM production in TM cells $[255,258]$ and proinflammatory cytokine Interleukin 6 and Secreted Protein Acidic Rich in cysteine, SPARC, in TM cells. The latter binds to ECM proteins and regulate matrix metalloproteinase expression. In addition, p38 MAP kinase is activated when TFGbeta binds to its I and II receptors, which initiates an E3 ubiquitin ligase (a commanding officer for protein pick up and removal). This accounts for inflammation, ubiquitination, and ECM TM cell balancing and re-balancing in AH dynamics [251-261].

Rho Kinase, (which is involved in cell migration, proliferation), is involved in actin cytoskeleton changes. CLAN, cross-linked actin network, has been observed in TM cells of eyes with glaucoma. [264] While the exact method of CLAN "tightening" the activity of TM cells is unclear, the TM cells express elevated levels of: laminin, alpha-smooth muscle actin, matrix assembly, actin stress fibers and myosin light-chain phosphorylation all of which are associated with ECM $[7,264]$. The latter TM factors were linked to increased contractile morphology. Rho Kinase inhibitors decrease fibronectin and alpha-smooth muscle actin [265]. Moreover, the Rho Kinase inhibitors reduce cell rigidity and increase aqueous outflow and reduce IOP by $30 \%$ after 3 hours in rabbit eyes [265]

Looking at the RGC/optic nerve side of glaucoma, several factors: (1) BDNF, brain derived neurotrophic factor and (2) JNK, (jun $\mathrm{n}$ terminal kinase), both neuroprotectant and pro-apoptotic, (3) phosphoinositide -3 kinase, (PI-3 kinase), a neuroprotectant, (4) PTEN, phosphatase and tensin homologue, linked to axon degeneration, (5) Bcl-2, an anti-apoptotic, (6) caspases, preapoptotic, and (7) calcium calpain pathway an apoptotic inducer, interact with one another and yet other proteins in an attempt to balance and re-balance cellular stress factors like elevated IOP with neuroprotective elements vs apoptotic neurodegenerative responses [267-281].

For example, BDNF is produced in retina and brain and is essential for RGC survival [260]. In glaucoma with increased IOP, reduced BDNF transport to the optic nerve results in caspase activation and apoptosis. However, intravitreal injection of neurotrophic factor in rats after optic nerve injury was neuro protective $[275,276]$ Table 3 . 
Table 3: Short List: Neuro Protective/Stabilizing vs Neuro Degenerative Elements in Glaucoma.

\begin{tabular}{|c|c|}
\hline Neuro Protective/stabilizing & Neuro Degenerative \\
\hline Statins & Elevated cholesterol, lipids, glycoprotein products; $[8,185,217]$ \\
\hline Thioredoxin: regulator of mitochondrial metabolism; ref.186 & $\begin{array}{l}\text { Oxidative stress, misfolded protein, caspases, mitochondrial/lysosome axis } \\
\text { dysfunction; [184] }\end{array}$ \\
\hline $\begin{array}{l}\text { MTORC 1: regulates lysosomal function for timely misfolded protein } \\
\text { removal; }[182,186,189,190,191]\end{array}$ & $\begin{array}{l}\text { Oxidative stress slows, stops autophagy, misfolded protein clearance, } \\
\text { provokes HSP, inflammation, immune and auto-immune; }[212,213,192,193] \\
\text { >IOP, RGC damage }\end{array}$ \\
\hline HSPs: helps misfolded protein clearance & Causes inflammation and autoimmune reaction RGC; $[3,184,187,190,195]$ \\
\hline ECM in balance, Matrix metalloproteinases & ECM with misfolded myocilin, fibrosis and excess deposits; > IOP; [222-229] \\
\hline Nitrous Oxide; > TM outflow & Pro/anti-inflammatory roles; [233-241] \\
\hline $\begin{array}{l}\text { Rho Kinase regulates Matrix metalloproteinase, its inhibition decreases } \\
\text { fibronectin and results in > TM outflow; }[239,233-237]\end{array}$ & Uninhibited it increases fibronectin and results in $<$ TM outflow and >IOP \\
\hline $\begin{array}{l}\text { TGF beta, pleotropic, activates MAP kinase and initiates E } 3 \text { Ligase: > } \\
\text { ubiquitination and misfolded protein clearance, }[257,258]\end{array}$ & May increase cell inflammation and IOP; ref [255-260,269-271,273] \\
\hline BDNF: anti-apoptotic, anti-autophagy, and anti- oxidative stres & $\begin{array}{l}\text { Anti-autophagy may increase back pileup of misfolded proteins and increase } \\
\text { inflammation }\end{array}$ \\
\hline
\end{tabular}

After cellular stress, such as uv radiation, heat shock, withdrawal of neurotrophic factors, or optic nerve transection, Jun N-Terminal Kinases, JNKs, pro-apoptotic pathway is activated. It is unclear if this pathway is purely apoptotic. Some studies have shown c- Jun activation may help RGC survival [277,278].

\section{Epigenetics and Glaucoma}

Hypoxia, oxidative stress and inflammation in the eye result in activation of protective transcription factors such as hypoxia inducible factor 1-alpha, Nrf2, (the major antioxidant transcription factor), and NFKB, (the major anti-inflammatory, immune transcription factor) which recruit enzymes that either open up protective gene activity, such as histone acetylase, or repress gene activity (histone deacetylase or histone methylation modifiers) by acting on the histones which enshroud the genes. The histones affect the expression of the genes without mutations, by inducing amongst other signal devices, noncoding RNA, MicroRNAs and long noncoding RNAs. These signals promote certain rescue pathways or in some cases, with over stressed systems lead to greater disease susceptibility by blocking helpful pathways. For example, the introduction of MicroRNA-483-3p to stressed human trabecular meshwork cells decreased ECM production and reduced fibrosis and enhanced aqueous outflow facility [286]. However in another gene signaling, MicroRNA 204 by decreasing FOXC1 as well as its target genes Clock, Plekshg5, ITG beta 1, Meis2 may cause Axenfeld Rieger Syndrome, (a childhood glaucoma with iridocorneal adhesions, ectropion uvea, atrophic iris holes, with possible systemic associations, thought to result from abnormal neural crest cell migration [6].

Comparing HSP70 expression levels in human lens capsule of pseudoexfoliaiton syndrome, PXS, with those who had pseudoexfoliaiton glaucoma, investigators recently demonstrated that HSP70 levels were significantly reduced in the PXS vs PXG compared to controls. Bisulfite sequencing of the of the transcription pre-coding and coding sites showed hypermethylation of the precoding sites only in the PXS individuals. There was also a reduced corresponding increase in DNA methyltransferase 3A only in the PXS individuals [293]. This implied a timely methylation at the PXS stage of the disease. In contrast, peripheral blood of PXS and PXG patients showed hypermethylation in the transcription coding region when compared to non-PXS controls. This would suggest a local tissue specific effect of the HSP70 chaperone [293].

Further analysis of the DNA spanning the precoding and coding region illustrated that there was decreased gene expression in the methylated vs the un-methylated reported gene vectors. DNA methyltransferase inhibitor used to treat the human lens epithelial cells restored the expression of HSP70 which correlated with methylation reduction at the precoding sites [293].

These findings not only increase our knowledge of HSP70 reduction in conjunction with hypermethylation, an established epigenetic mechanism for reduced genetic expression, but may also provide a platform for regulating the early phase of pseudoexfoliaiton glaucoma.

\section{Discussion}

One can infer from the multitude of neuro-degenerative vs neuro-protective factors that a rather complex series of checks and balances may be operational in the RGCs, the optic nerve and the TM over the course of time. That said, while IOP control and the dynamics of TM outflow and the flexibility of the ECM to deposits and contractile mechanics are major factors in current glaucoma therapeutics, RGC, optic nerve and brain [287] homeostasis, its mitochondrial energy producing and sustaining capabilities, the ability to clear misfolded protein, and exert antioxidant, anti-inflammatory, anti-autoimmune, and anti-apoptotis signal pathways also constitute a major neuro-protective defense arsenal that will probably guide the glaucoma therapeutics of the future.

Thus far, targeting the complexity and numbers of neuroprotective agents seems to be a daunting task. Over 100 neuro-protective drug candidates have failed to demonstrate 
patient benefit. For example, Memantine, a N-methyl-D-aspartate, NMDA subtype of glutamate receptor antagonist already in use for Alzheimer's disease, while convincing in animal models, five years and $\$ 100$ million dollars later, failed to halt progression of visual field loss in glaucoma patients [287].

Also, animal studies which rely on histopathologic endpoints to examine the effectiveness of treatment are not practical in humans for ethical reasons. Perhaps newer methods of following RGC damage and demise such as: detecting apoptosing retinal ganglion cell technique, DARC, in vivo or methods of measuring mitochondrial depolarization, excessive glutamate receptor activation resulting in excess PTP, mitochondrial permeability transition pore, and excess of cytochrome c formation, (a preapoptotic), or overactivation of NMDA and non-NMDA glutamate receptors with resulting excess NO, refined VEP, visual evoked potential and PERG, pattern electroretinogram will serve as better guides in developing neuroprotectants [287].

Early data in CoQ10, (a component of mitochondrial respiratory chain by which ATP is produced) may be promising. Because of its role in protecting lipids and DNA from oxidative stress, it may inhibit mitochondrial pore formation and cytochrome release leading to apoptosis [288,289].

Citicoline, a neuro protectant used in Alzheimer's Disease possibly interfering with the deposition of neurotoxic proteins such as beta amyloid [290] (and associated with improvement of rigidity, bradykinesia and tremor in Parkinson's), has shown antiapoptotic effects in RGC mitochondria-dependent cell death [291]. Rats after nerve crush injury had a citicoline anti-apoptotic effect as well as an expression of $\mathrm{Bcl}-2$, which is one of the main anti-apoptotic proteins [292].

\section{Conclusion}

Genomic, proteomic, epigenetic and molecular signaling pathways in the development of glaucoma represent the language of the next frontier to be conquered in human disease. Understanding the fine details of these pathways will provide a way to differentiate phenotypic/genotypic variances as well as better lines of therapeutic intervention.

Insights into the balancing and re-balancing of: (1) oxidative stress, (2) misfolded proteins, (3) heat shock proteins (including their immune-autoimmune/inflammatory and microglial effects), (4) key transcription factors, signal transducers, and chromatin gene modifiers, (5) mitochondrial/ lysosome protein misfolded clearance pathway, immune and proteolytic, and (6) the control of the caspases to prevent apoptosis may open directives for treatment of the non IOP part of glaucoma and neurodegenerative disease.

\section{Acknowledgement}

None.

\section{Conflict of Interest}

Author declares no conflict of interest.

\section{References}

1. Childhood Glaucoma, Glaucoma Research foundation.

2. Mancino R, Martucci A, Cesareo M, Giannini C, Corasaniti MT, et al. (2018) Glaucoma and Alzheimer Disease: One Age-Related Neurodegenerative Disease of the Brain. Curr Neuropharmacol 16(7): 971-977.

3. Gupta N, Greenberg G, de Tilly LN, Gray B, Polemidiotis M (2009) Atrophy of the lateral geniculate nucleus in human glaucoma detected by magnetic resonance imaging. Br J Ophthalmol 93(1): 56-60.

4. Weinreb RN, Aung T, Medeiros FA (2014) The Pathophysiology and Treatment of Glaucoma A Review. JAMA 311(18): 1901-1911.

5. Tham YC, Li X, Wong TY, Quigley HA, Aung T, et al. (2014) Global prevalence of glaucoma and projections of glaucoma burden through 2040: A systematic review and meta-analysis. Ophthalmology 121(11): 2081-2090.

6. Gauthier AC, Liu J (2017) Epigenetics and signaling pathways in glaucoma. Biomed Res Int 2017: 5712341.

7. Tsai T, Grotegut P, Reinehr S, Joachim SC (2019) Role of Heat Shock Proteins in Glaucoma. Int J Mol Sci 20(20): 5160.

8. Choquet H, Wiggs JL, Khawaja AP (2020) Clinical implications of recent advances in primary open angle glaucoma genetics. Eye (Lond) 34: 29 39.

9. Hoffman TJ, Tang H, Thornton TA, Caan B, Haan M et al. (2014) Genomewide association and admixture analysis of glaucoma in women's health initiative. Hum Mol Genet 23(24): 6634-6643.

10. Taylor KD, Guo X, Zangwill LM, Liebman JM, Girkin CA, et al. (2019) Genetic architecture of primary open angle glaucoma in individuals of African descent: the African Descent and Glaucoma Evaluation Study III. Ophthalmology 126(1): 38-48.

11. Bonnemaijer PWM, Iglesias AI, Nadkarni G N, Sanyiwa AJ, Hassan HG, et al. (2018) Genome wide association study of primary open angle glaucoma in continental and admixed African populations. Hum Genet 137(10): 847-862.

12. Khachartyran N, Medeiros FA, Sharpsten L, Bodw C, Sample PA, et al. (2015) The African Descent and Glaucoma Evaluation Study: predictors of visual field damage in glaucoma suspects. Am J Ophthalmol 159(4): 777-787.

13. Kyari F, Abdull MM, Bastawrous A, Gilbert CE, Faal H (2013) Epidemiology of glaucoma in sub-Saharan Africa: prevalence, incidence and risk factors. Middle East Afr J Ophthalmol 20(2): 111-125.

14. Williams SE, Carmichael TR, Allingham RR, Hauser M, Ramsey M (2015) The genetics of POAG in black South Africans: a candidate gene association study. Sci Rep 5: 8378.

15. Kawakami K, Sato S, Ozaki H, Ikeda K (2000) Six family genes- structure and function as transcription factors and their roles in development. Bioassays 22(7): 616-626.

16. Kumar JP (2009) The sine oculis homeobox (SIX) family of transcription factors as regulators of development and disease. Cell Mol Life Sci 66(4): 565-583.

17. Iglesias AI, Springelkamp H, van der Linde H, Severijnen LA, Amin N, et al. (2014) Exome sequencing and functional analyses suggest that SIX6 is a gene involved in an altered proliferation-differentiation balance early in life and optic nerve degeneration at old age. Hum Mol Genet 23(5): 1320-1332.

18. Carnes MU, Liu YP, Allingham RR, Whigham BT, Havens S, et al. (2014) Discovery and functional annotation of SIX6 variants in primary openangle glaucoma. PLoS Genet 10(5): e1004372.

19. Skowronska Krawczyk D, Zhao L, Zhu J, Weinreb RN, Cao G, et al. (2015) P16INK4a upregulation mediated by six6 defines retinal ganglion cell pathogenesis in glaucoma. Mol Cell 59(6): 931-940. 
20. Choquet H, Thai KK, Yin J, Hoffmann TJ, Kvale MN, et al. (2017) A large multi-ethnic genome-wide association study identifies novel genetic loci for intraocular pressure. Nat Commun 8: 2108

21. Hysi PG, Cheng CY, Springelkamp H, Macgregor S, Bailey JNC, et al (2014) Genome-wide analysis of multi- ancestry cohorts identifies new loci influencing intraocular pressure and susceptibility to glaucoma. Nat Genet 46(10): 1126-1130.

22. Ramdas WD, Van Koolwijk LM, Ikram MK, Jansonius NM, De Jong PT, et al. (2010) A genome-wide association study of optic disc parameters. PLoS Genet 6(6): e1000978.

23. Khawaja AP, Cooke Bailey JN, Wareham NJ, Scott RA, Simcoe M, et al. (2018) Genome-wide analyses identify 68 new loci associated with intraocular pressure and improve risk prediction for primary openangle glaucoma. Nat Genet 50(6): 778-782.

24. Lu Y, Vitart V, Burdon KK, Khor CC, Bykhovskaya Y, et al. (2013) Genomewide association analyses identify multiple loci associated with central corneal thickness and keratoconus. Nat Genet 45(2): 155-163.

25. Ivarsdottir EV, Benonisdottir S, Thorleifsson G, Sulem P, Oddsson A et al. (2019) Sequence variation at ANAPC1 accounts for $24 \%$ of the variability in corneal endothelial cell density. Nat Commun 10(1): 1284

26. Klein RL, Zeiss C, Chew EY et al. (2005) Complement factor $H$ polymorphism in age-related macular degeneration. Science 308(5720): 385-389.

27. Albert 0 Edwards, Robert Ritter, Kenneth J Abel, Alisa Manning, Carolien Panhuysen, et al. (2005) Complement factor H polymorphism and agerelated macular degeneration. Science 308(5720): 421-424

28. Jonathan L Haines, Michael A Hauser, Silke Schmidt, William K Scott, Lana M Olson, et al. (2005) Complement factor $\mathrm{H}$ variant increases the risk of age-related macular degeneration. Science 308(5720): 419-421.

29. Rosenfeld PJ, Moshfegi AA, Puliafito CA (2005) Optical coherence tomography findings after an intravitreal injection of bevacizumab (Avastin) for neovascular age related macular degeneration. Ophthalmic Surg Lasers Imaging 36(4): 331-335

30. Ronald Klein, Michael D Knudtson, Barbara E K Klein, Tien Y Wong Mary Frances Cotch, et al. (2008) Inflammation, complement factor $\mathrm{H}$, and age-related macular degeneration: The Multi-ethnic Study of Atherosclerosis. Ophthalmology 115(10): 1742-1749.

31. Shiga Y, Akiyama M, Nishiguchi KM, Sato K, Shimozawa N, et al. (2018) Genome-wide association study identifies seven novel susceptibility loci for primary open-angle glaucoma. Hum Mol Genet 27(8): 486-496.

32. Souma T, Tompson SW, Thomson BR, Siggs OM, Kizhatil K, et al. (2016) Angiopoietin receptor TEK mutations underlie primary congenital glaucoma with variable expressivity. J Clin Invest 126(7): 2575-2587.

33. Kizhatil K, Ryan M, Marchant JK, Henrich S, John SW (2014) Schlemm's canal is a unique vessel with a combination of blood vascular and lymphatic phenotypes that forms by a novel developmental process. PLoS Biol 12(7): e1001912.

34. Aspelund A, Tammela T, Antila S, Nurmi H, Leppanen VM, et al. (2014) The Schlemm's canal is a VEGF-C/VEGFR-3- responsive lymphatic-like vessel. J Clin Invest 124(9): 3975-3986.

35. Astafurov K, Elhawy E, Ren L, Dong CQ, Igboin C, et al. (2014) Oral microbiome link to neurodegeneration in glaucoma. Plos One 9(9): e104416.

36. Cheng L, Yang X, Kain AD, Powell DW, Kuehn MH, et al. (2010) Glaucomatous Tissue Stress and the Regulation of Immune Response through Glial Toll-like Receptor Signaling. Invest Ophthalmol Vis Sci 51(11): 5697-5707.

37. O'Callaghan J, Cassidy PS, Humphries P (2017) Open angle glaucoma: therapeutically targeting the extracellular matrix of the conventional outflow pathway. Expert Opin Ther Targets 21(11): 1037-1050.
38. Tin Aung, Mineo Ozaki, Mei Chin Lee, Ursula Schlötzer-Schrehardt, Gudmar Thorleifsson, et al. (2017) Genetic association study of exfoliation syndrome identifies a protective rare variant at LOXL1 and five new susceptibility loci. Nat Genet 49(7): 993-1004.

39. Ritch R, Schlotzer-Schrehardt U, Konstas AG (2003) Why is glaucoma associated with exfoliation syndrome? Prog Retin Eye Res 22(3): 253275 .

40. Ritch R (2017) Ocular and systemic manifestations of exfoliation syndrome. J Glaucoma 23(8 supp 1): S1-8.

41. Ritch R (1994) Exfoliation syndrome-the most common identifiable cause of open-angle glaucoma. J Glaucoma 3(2): 176-177.

42. Aung T, Pasutto F, Wiggs JL, Khor CC, Gudmar, et al. (2017) Genetic association study of exfoliation syndrome identifies a protective rare variant at LOXL1 and five new susceptibility loci. Nat Genet 49(7): 9931004.

43. Schlötzer-Schrehardt U, Körtje K, Erb C. (2001) Energy-filtering transmission electron microscopy (EFTEM) in the elemental analysis of pseudoexfoliative material. Curr Eye Res 22(2): 154-162.

44. Aung T, Ozaki M, Mizoguchi T, Allingham R, Li Z, et al. (2015) A common variant mapping to CACNA1A is associated with susceptibility to exfoliation syndrome. Nat Genet 47(4): 387-392.

45. Lucero HA, Kagan HM (2006) Lysyl oxidase and oxidative enzyme and effector cell function. Cell Mol Life Sci 63(19-20): 2304-2316.

46. Fount P, Haidich A, Chatzikyriakidou A, Salonikiou A, Anastasopoulos, et al. (2015) Ethnicity-Based Differences in the Association of LOXL1 Polymorphisms with Pseudoexfoliation/Pseudoexfoliative Glaucoma: A Meta-Analysis. Ann Hum Genet 79(6): 431-450.

47. Pasquale L, Borrás T, Fingert J, Wiggs J, Ritch R (2016) Exfoliation syndrome: assembling the puzzle pieces. Acta Ophthalmol. 94(6): e505512.

48. Padhy B, Nanda G, Chowdhury M, Padhi D, Rao A, et al. (2014) Role of an extracellular chaperone, Clusterin in the pathogenesis of Pseudoexfoliaiton Syndrome and Pseudoexfoliaiton Glaucoma. Exp Eye Res 127: 69-76.

49. Dubey S, Hejtmancik J, Krishnadas S, Sharmila R, Haripriya A, et al. (2015) Evaluation of genetic polymorphisms in clusterin and tumor necrosis factor-alpha genes in South Indian individuals with pseudoexfoliaiton syndrome. Curr Eye Res 40(12): 1218-1224.

50. Fan B, Pasquale L, Kang J, Levkovitch-Verbin H, Haines Wiggs J, et al. (2015) Association of clusterin (CLU) variants and exfoliation syndrome: An analysis in two Caucasian studies and a meta-analysis. Exp Eye Res 139: $115-222$

51. Scuderi G, Nucci C, Tomei M (1998) Pseudoexfoliation syndrome in a patient with lattice corneal dystrophy. Int Ophthalmol 22(4): 195-196.

52. I Viard, P Wehrli, L Jornot, R Bullani, JL Vechietti,, et al. (1999) Clusterin gene expression mediates resistance to apoptotic cell death induced by heat shock and oxidative stress. J Invest Dermatol 112(3): 290-296.

53. Zenkel M, Kruse FE, Junemann AG, Naumann GOH, Schotzer-Schrehardt U (2006) Clusterin deficiency in eyes with pseudoexfoliation syndrome may be implicated in the aggregation and depletion of pseudoexfoliative material. Invest Ophthal Vis Sci 47(5): 1982-1990.

54. Gian Marco Ghiggeri, Maurizio Bruschi, Giovanni Candiano, Maria Pia Rastaldi, Francesco Scolari, et al. (2002) Depletion of clusterin in renal diseases causing nephrotic syndrome. Kidney Int 62(6): 2184-2194.

55. Mark E Rosenberg, Richard Girton, David Finkel, David Chmielewski, Arthur Barrie, et al. (2002) Apolipoprotein J/clusterin prevents a progressive glomerulopathy of aging. Mol Cell Biol 22(6): 1893-1902.

56. Janig E, Stumptner C, Fuchsbichler A, Denk H, Zatloukal K (2005) Interaction of stress proteins with misfolded keratin. Eur J Cell Biol 84(2-3): 329-339. 
57. Fink AL (1998) Protein aggregation: folding aggregates, inclusion bodies and amyloid. Folding and Design 13(1): R9-R23.

58. Kang J, Loomis S, Wiggs J, Stein J, Pasquale L (2012) Demographic and geographic features of exfoliation glaucoma in 2 United States-based prospective cohorts. Ophthalmology 119(1): 27-35.

59. Pasquale L, Jiwani A, Zehavi-Dorin T, Majd A, Rhee D, et al. (2014) Solar exposure and residential geographic history in relation to exfoliation syndrome in the United States and Israel. JAMA Ophthalmol 132(12): 1439-1445.

60. Fan B, Pasquale L, Rhee D, Li T, Haines J, et al. (2011) LOXL1 promoter haplotypes are associated with exfoliation syndrome in a U.S. Caucasian population. Invest Ophthalmol Vis Sci 52(5): 2372-2378.

61. Fount P, Haidich A, Chatzikyriakidou A, Salonikiou A, Anastasopoulos E,Pappas T, et al. (2015) Ethnicity-Based Differences in the Association of LOXL1 Polymorphisms with Pseudoexfoliation/Pseudoexfoliative Glaucoma: A Meta-Analysis. Ann Hum Genet 79(6): 431-450.

62. Ritland J, Egge K, Lydersen S, Juul R, Semb S (2004) Exfoliative glaucoma and primary open-angle glaucoma: associations with death causes and comorbidity. Acta Ophthalmol Scand 82(4): 401-404.

63. Gökce S, Deren T, Köz O, Yilmaz P, Başkan C, et al. (2016) Evaluation of Carotid Intima Media Thickness and Renal Artery Resistive Index in Patients with Pseudoexfoliaiton Syndrome: A Prospective Case-Contro Study. J Glaucoma 25(5): e559-561.

64. Wang W, He M, Zhou M, Zhang X (2014) Ocular pseudoexfoliation syndrome and vascular disease: a systematic review and meta-analysis. PLoS One 9(3): e92767.

65. Ringvold A, Blika S, Sandvik L (1997) Pseudo-exfoliation and mortality. Acta Ophthalmol Scand 75(3): 255-256.

66. Grodum K, Heiji A, Bengtsson B (2004) Glaucoma and mortality. Graefes Arch Clin Exp Ophthalmol 242: 397-401.

67. Shrum K, Hattenhauer M, Hodge D (2000) Cardiovascular and cerebrovascular mortality associated with ocular pseudoexfoliation. Am J Ophthalmol 129(1): 83-86.

68. llingham R, Loftsdottir M, Gottfredsdottir M, Thorgeirsson E, Jonasson F, et al. (2001) Pseudoexfoliation syndrome in Icelandic families. Br J Ophthalmol 85(6): 702-707

69. Tarkkanen A, Kivela T (2014) Mortality in primary open-angle glaucoma and exfoliative glaucoma. Eur J Ophthalmol 24(5): 718-721.

70. Ascaso F, Huerva V, Grzybowski A (2015) Epidemiology, Etiology, and Prevention of Late IOL-Capsular Bag Complex Dislocation: Review of the Literature. J Ophthalmol 2015: 805706.

71. Inoue K, Okugawa K, Oshika T, Amano S (2003) Morphological study of corneal endothelium and corneal thickness in pseudoexfoliation syndrome. Jpn J Ophthalmol 47: 235-239.

72. Helbig H, Schlötzer-Schrehardt U, Noske W, Kellner U, Foerster M, et al. (1994) Anterior- chamber hypoxia and iris vasculopathy in pseudoexfoliation syndrome. Ger J Ophthalmol 3(3): 148-153.

73. Eroglu F, Asena L, Simsek C, Kal A, Yilmaz G (2015) Evaluation of choroidal thickness using enhanced depth imaging by spectral-domain optical coherence tomography in patients with pseudoexfoliaiton syndrome. Eye (Lond) 29(6): 791-796.

74. Turan-Vural E, Yenerel N, Okutucu M, Yildiz E, Dikmen N (2015) Measurement of Subfoveal Choroidal Thickness in Pseudoexfoliation Syndrome Using Enhanced Depth Imaging Optical Coherence Tomography. Ophthalmologica 233(3-4): 204-208.

75. Kocaturk T, Isikligil I, Uz B, Dayanir V, Dayanir Y (2016) Ophthalmic artery blood flow parameters in pseudoexfoliation glaucoma. Eur ] Ophthalmol 26(2): 124-127.

76. Dursun F, Ozec AV, Aydin H, Topalkara A, Dursun A, et al. (2015) Total oxidative stress, paraoxonease and arylesterase levels at patients with pseudoexfoliation syndrome and pseudoexfoliative glaucoma. Int J Ophthalmol 8(5): 985-990.

77. Vulovic TS, Pavlovic S, Zdravkovic N (2015) Proinflammatory Cytokines Induce XFG Development. Ocul Immunol Inflamm 24(6): 671-677.

78. Sharma S, Bollinger KE, Kodeboyina SK, Zhi W, Patton J, et al. (2018) Proteomic alterations in aqueous humor from patients with primary open angle glaucoma. Invest Ophthalmol Vis Sci 59: 2635-2643.

79. Abu-Hassan DW, Acott TS, Kelley MJ (2014) The trabecular meshwork: a basic review of form and function. J Ocul Biol 2: 9.

80. Wang H, Li M, Zhang Z, Xue H, Chen X, et al. (2019) Physiological function of myocilin and its role in the pathogenesis of glaucoma in the trabecular meshwork (Review). International J of Molec Med 43: 671-681.

81. Donegan RK, Hill SE, Freeman DM, Nguyen E, Orwig SD, et al. (2015) Structural basis for misfolding in myocilin-associated glaucoma. Hum Mol Genet 24 (21): 2111-2124.

82. Guan Y, Li J, Zhan T, Wang JW, Yu JB, et al. (2016) Idebenone maintains survival of mutant myocilin cells by inhibiting apoptosis. Chin Med J (Engl) 129: 2001-2004

83. Nag A, Lu H, Arno M, Iglesias AI, Bonnemaijer P, et al. (2017) Evaluation of the myocilin mutation gln368stop demonstrates reduced penetrance for glaucoma in European populations. Ophthalmology 124: 547-553.

84. Lam DS, Leung YF, Chua JK, Baum L, Fan DS, et al. (2000) Truncations in the TIGR gene in individuals with and without primary open-angle glaucoma. Invest Ophthalmol Vis Sci 41: 1386-1391.

85. Shepard AR, Jacobson N, Millar JC, Pang IH, Steely T, et al. (2007) Glaucoma-causing myocilin mutants require the Peroxisomal targeting signal-1 receptor (PTS1R) to elevate intraocular pressure. Hum Mol Genet 16: 609-617.

86. Joe MK, Nakaya N, Abu-Asab M, Tomarev SI (2015) Mutated myocilin and heterozygous Sod2 deficiency act synergistically in a mouse model of open-angle glaucoma. Hum Mol Genet 24: 3322-3334.

87. Joe MK, Tomarev SI (2010) Expression of myocilin mutants sensitizes cells to oxidative stress-induced apoptosis: Implication for glaucoma pathogenesis. Am J Pathol 176: 2880-2890.

88. Hill SE, Donegan RK, Lieberman RL (2014) The glaucoma-associated olfactomedin domain of myocilin forms polymorphic fibrils that are constrained by partial unfolding and peptide sequence. J Mol Biol 426: 921-935.

89. Liu Y, Vollrath D (2004) Reversal of mutant myocilin non-secretion and cell killing: Implications for glaucoma. Hum Mol Genet 13: 1193-1204.

90. Joe MK, Sohn S, Hur W, Moon Y, Choi YR, (2003) Accumulation of mutant myocilins in ER leads to ER stress and potential cytotoxicity in human trabecular meshwork cells. Biochem Biophys Res Commun 312: 592 600 .

91. Zhao J, Wang S, Zhong W, Yang B, Sun L, et al. (2016) Oxidative stress in the trabecular meshwork (Review). Int J Mol Med 38: 995-1002.

92. Grootjans J, Kaser A, Kaufman RJ, Blumberg RS (2016) The unfolded protein response in immunity and inflammation. Nat Rev Immunol 16 : 469-484.

93. Peters JC, Bhattacharya S, Clark AF, Zode GS (2015) Increased endoplasmic reticulum stress in human glaucomatous trabecular meshwork cells and tissues. Invest Ophthalmol Vis Sci 56: 3860-3868.

94. Huard DJ, Lieberman RL (2018) Progress toward development of a proteostasis drug for myocilin-associated glaucoma. Future Med Chem 10: 1391-1393.

95. Huard DJE, Crowley VM, Du Y, Cordova RA, Sun Z, et al. (2018) Trifunctional high-throughput screen identifies promising scaffold to inhibit Grp94 and treat myocilin-associated glaucoma. ACS Chem Biol 13: 933-941. 
96. Stothert AR, Suntharalingam A, Huard DJ, Fontaine SN, Crowley VM, et al. (2014) Exploiting the interaction between Grp94 and aggregated myocilin to treat glaucoma. Hum Mol Genet 23: 6470-6480.

97. Stothert AR, Suntharalingam A, Tang X, Crowley VM, Mishra SJ, et al. (2017) Isoform-selective Hsp90 inhibition rescues model of hereditary open-angle glaucoma. Sci Rep 7: 17951.

98. Stothert AR, Fontaine SN, Sabbagh JJ, Dickey CA (2016) Targeting the ERautophagy system in the trabecular meshwork to treat glaucoma. Exp Eye Res 144: 38-45.

99. Qiu Y, Shen X, Shyam R, Yue BY, Ying H (2014) Cellular processing of myocilin. PLoS One 2014: 92845.

100. Keller KE, Wirtz MK (2017) Working your SOCS off: The role of ASB10 and protein degradation pathways in glaucoma. Exp Eye Res 158: 154-

101. Hamanaka T, Kimura M, Sakurai T, Ishida N, Yasuda J, et al. (2017) A histologic categorization of aqueous outflow routes in familial openangle glaucoma and associations with mutations in the MYOC gene in Japanese patients. Invest Ophthalmol Vis Sci 58: 2818-2831.

102. Vollrath D, Liu Y (2006) Temperature sensitive secretion of mutant myocilins. Exp Eye Res 82: 1030-1036

103. Caballero M, Borras T (2001) Inefficient processing of an olfactomedin deficient myocilin mutant: Potential physiological relevance to glaucoma. Biochem Biophys Res Commun 282: 662-670.

104. Yam GH, Gaplovska-Kysela K, Zuber C, Roth J (2007) Aggregated myocilin induces Russell bodies and causes apoptosis: Implications for the pathogenesis of myocilin-caused primary open-angle glaucoma. Am J Pathol 170: 100-109.

105. Zode GS, Kuehn MH, Nishimura DY, Searby CC, Mohan K, et al. (2011) Reduction of ER stress via a chemical chaperone prevents disease phenotypes in a mouse model of primary open angle glaucoma. J Clin Invest 121: 3542-3553.

106. Maddineni P, Kasetti RB, Zode GS (2018) Methods for analyzing endoplasmic reticulum stress in the trabecular meshwork of glaucoma models. Methods Mol Biol 1695: 121-134.

107. Chong WC, Shastri MD, Eri R (2017) Endoplasmic reticulum stress and oxidative stress: A vicious nexus implicated in bowel disease pathophysiology. Int J Mol Sci 18: E771.

108. Grootjans J, Kaser A, Kaufman R, Blumberg RS (2016) The unfolded protein response in immunity and inflammation. Nat Rev Immunol16: 469-484.

109. Peters JC, Bhattacharya S, Clark AF, Zode GS (2015) Increased endoplasmic reticulum stress in human glaucomatous trabecular meshwork cells and tissues. Invest Ophthalmol Vis Sci 5(56): 38603868.

110. Wang N, Chintala SK, Fini ME, Schuman JS (2001) Activation of a tissue-specific stress response in the aqueous outflow pathway of the eye defines the glaucoma disease phenotype. Nat Med 7: 304-309.

111. Itakura T, Peters DM, and Fini ME (2015) Glaucomatous MYOC mutations activate the IL-1/NF- $\mathrm{KB}$ inflammatory stress response and the glaucoma marker SELE in trabecular meshwork cells. Mol Vis 21: 1071-1084.

112. Fini ME (2017) Another piece of the puzzle: MYOC and myocilin glaucoma. Invest Ophthalmol Vis Sci 58: 5319.

113. Li G, Cui G, Dismuke WM, Navarro I, Perkumas K, et al. (2017) Differential response and withdrawal profile of glucocorticoid-treated human trabecular meshwork cells. Exp Eye Res 155: 38-46.

114. Ashworth Briggs EL, Toh T, Eri R, Hewitt AW, Cook AL (2015) TIMP1 TIMP2 and TIMP4 are increased in aqueous humor from primary open angle glaucoma patients. Mol Vis 21:1162-1172.

115. Kasetti RB, Phan TN, Millar JC, Zode GS (2016) Expression of mutant myocilin induces abnormal intracellular accumulation of selected extracellular matrix proteins in the trabecular meshwork. Invest Ophthalmol Vis Sci 57: 6058-6069.

116. Joe MK, Sohn S, Choi YR, Park H, Kee C (2005) Identification of flotillin-1 as a protein interacting with myocilin: Implications for the pathogenesis of primary open-angle glaucoma. Biochem Biophys Res Commun 336: 1201-1206.

117. Zode GS, Sharma AB, Lin X, Searby CC, Bugge K, et al. (2014) Ocular-specific ER stress reduction rescues glaucoma in murine glucocorticoid-induced glaucoma. J Clin Invest 124: 1956-1965.

118. Ho H, Htoon HM, Yam GH, Toh LZ, Lwin NC, et al. (2017) Altered anterior segment biometric parameters in mice deficient in SPARC. Invest Ophthalmol Vis Sci 58: 386-393.

119. Li Y, Aroca-Aguilar JD, Ghosh S, Sánchez-Sánchez F, Escribano J, et al (2006) Interaction of myocilin with the C-terminal region of hevin. Biochem Biophys Res Commun 339: 797-804.

120. Burns JN, Turnage KC, Walker CA, Lieberman RL (2011) The stability of myocilin olfactomedin domain variants provides new insight into glaucoma as a protein misfolding disorder. Biochemistry 50: 58245833.

121. Burns JN, Orwig SD, Harris JL Watkins JD, Vollrath D, et al. (2010) Rescue of glaucoma-causing mutant myocilin thermal stability by chemical chaperones. ACS Chem Biol 5: 477-487.

122. Gobeil S, Letartre L, Raymond V (2006) Functional analysis of the glaucoma-causing TIGR/myocilin protein: Integrity of amino-terminal coiled-coil regions and olfactomedin homology domain is essential for extracellular adhesion and secretion. Exp Eye Res 82: 1017-1029.

123. Burns JN, Orwig SD, Harris JL Watkins JD, Vollrath D, et al. (2010) Rescue of glaucoma-causing mutant myocilin thermal stability by chemical chaperones. ACS Chem Biol 5: 477-487.

124. Aroca-Aguilar JD, Sánchez-Sánchez F, Martínez-Redondo F, CocaPrados M, Escribano J (2008) Heterozygous expression of myocilin glaucoma mutants increases secretion of the mutant forms and reduces extracellular processed myocilin. Mol Vis14: 2097-2108.

125. Greenstein V. C, Seiple W, Liebman J, Ritch R, (2001) Retinal pigment epithelial dysfunction in patients with pigment dispersion syndrome. Arch Ophthalmol 119(9): 1291-1295.

126. Siddiqui Y, Ten Hulzen RD, Cameron JD, Hodge D, Johnson D.H (2003) What is the risk of developing pigmentary glaucoma from pigment dispersion syndrome. American Journal of Ophthalmology 135 (6): 794-799.

127. DG Campbell (1979) Pigmentary dispersion and glaucoma. Archives of Ophthalmology 97 (9): 1667-1672.

128. Potash SD, Tello C, Liebmann J, Ritch R (1994) Ultrasound biomicroscopy in pigment dispersion syndrome. Ophthalmology 101(2): 332-339.

129. Krukenberg F (1899) Bilateral congenital melanosis of the cornea. clinical monthly sheets for ophthalmology 37: 254-258.

130. HS S, FA B (1949) Pigmentary glaucoma: a rare clinical entity. American Journal of Ophthalmology 32(1): 90-92.

131. Murrell WJ, Shihab Z, Lamberts DW, Avera B (1986) The corneal endothelium and central corneal thickness in pigmentary dispersion syndrome. Arch Ophthalmol 104(6): 845-846.

132. Lehto I, Ruusuvaara P, Setälä K (1990) Corneal endothelium in pigmentary glaucoma and pigment dispersion syndrome. Acta Ophthalmologica 68(6): 703-709.

133. Prince AM, Ritch R (1986) Clinical signs of the Pseudoexfoliaiton syndrome. Ophthalmology 93(6): 803-807.

134. Alvarado JA, Murphy CG (1992) Outflow obstruction in pigmentary and primary open angle glaucoma. Arch Ophthalmol 110(12): 17691778 . 
135. Von Hippel E (1901) On the pathological anatomy of glaucoma. Archives of Ophthalmology 52: 498.

136. Migliazzo CV, Shaffer RN, Nykin R, Magee S (1986) Long-term analysis of pigmentary dispersion syndrome and pigmentary glaucoma. Ophthalmol 93(12): 1528-1536.

137. Niyadurupola N, Broadway DC (2008) Pigment dispersion syndrome and pigmentary glaucoma-a major review. Clin Exp Ophthalmology 36(9): 868-882.

138. Andersen JS, Pralea AM, DelBono EA, JL Haines, MB Gorin, et al. (1997) A gene responsible for the pigment dispersion syndrome maps to chromosome 7q35-q36. Archives of Ophthalmology 115(3): 384-388.

139. Robinson L.J, Weremowicz S, Morton CC, Michel T (1994) Isolation and chromosomal localization of the human endothelial nitric oxide synthase (NOS3) gene. Genomics 19 (2): 350-357.

140. Davidge ST, Baker PN, McLaughlin MK, Roberts JM (1995) Nitric oxide produced by endothelial cells increases production of eicosanoids through activation of prostaglandin $\mathrm{H}$ synthase. Circulation Research 77(2): 274-283.

141. Steudel W, Ichinose F, Huang PL, W E Hurford, R C Jones, et al. (1997) pulmonary vasoconstriction and hypertension in mice with targeted disruption of the endothelial nitric oxide synthase (NOS 3) gene. Circulation Research 81(1): 34-41.

142. AL Vincen, Alex V Levin, Megan Priston, Billingsley G, Buys Y, et al. (2002) Digenic inheritance of early-onset glaucoma: CYP1B1, potential modifier gene. American Journal of Human Genetics 70(2): 448-460.

143. M Faucher, M Anctil JL, Rodriguez MA, Jean Morissette, Vincent Raymond, et al. (2002) Founder TIGR/myocilin mutations for glaucoma in the Québec population. Human Molecular Genetics 11(18): 2077-2090.

144. Alward WL, A Tim Johnson, Sohan S Hayreh, M Bridget Zimmerman Kwon YH, Khannaetal CI, et al. (2002) Variations in the myocilin gene in patients with open-angle glaucoma. Archives of Ophthalmology 120(9): 1189-1197.

145. Wolf C, Gramer E, Muïler-Myhsok B, Francesca Pasutto, Gwendolyn Gramer, Bernd Wissinger, et al. (2010) Lysyl oxidase- like 1 gene polymorphisms in German patients with normal tension glaucoma pigmentary glaucoma and exfoliation glaucoma. Journal of Glaucoma 19(2): 136-141

146. Rao KN, Ritch R, Dorairaj SK, Internet Kaur, Jeffrey M Liebmann, et al. (2008) Exfoliation syndrome and exfoliation glaucoma-associated LOXL1 variations are not involved in pigment dispersion syndrome and pigmentary glaucoma, Molecular Vision 14: 1254-262.

147. Giardina F, Oddone F, Lepre T, Luciano Quarantine, Paolo Frezzotti, et al. (2014) Common sequence variants in the LOXL1gene in pigment dispersion syndrome and pigmentary glaucoma. BMC Ophthalmology 14(1): 52.

148. Baulmann DC, Ohlmann A, Flügel Koch C, Goswami S, Cvekl A, Tamm ER (2002) Pax6 heterozygous eyes show defects in chamber angle differentiation that are associated with a wide spectrum of other anterior eye segment abnormalities. Mechanisms of Development 118 (1-2): 3-17.

149. Berry FB, Lines MA, Oas JM, Tim Footz, D Alan Underhill, et al. (2006) Functional interactions between FOXC1 and PITX2 underlie the sensitivity to FOXC1 gene dose in Axenfeld-Rieger syndrome and anterior segment dysgenesis. Human Molecular Genetics 15(6): 905919.

150. Seifi M, Footz T, Taylor SAM, Elhady G M, Abdalla EM, et al. (2016) Novel PITX2 gene mutations in patients with Axenfeld-Rieger syndrome. Acta Ophthalmologica 94(7): e571-e579.

151. Gould DB, Smith RS, John SWM (2004) Anterior segment development relevant to glaucoma. The International Journal of Developmental Biology 48(8-9): 1015-1029.
152. Urabe K, Aroca P, Tsukamoto K (1994) The inherent cytotoxicity of melanin precursors: a revision Biochimica et Biophysica Acta (BBA). Molecular Cell Research 1221(3): 272-278.

153. Sturm RA, Frudakis TN (2004) Eye colour: portals into pig-mentation genes and ancestry. Trends in Genetics 20(8): 327-332.

154. Duffy DL, Montgomery GW, Chen W, Zhen Zhen Zhao, Lien Le, et al. (2007) A three-single-nucleotide polymorphism haplotype in intron 1 of OCA2 explains most human eye-color variation. American Journal of Human Genetics 80(2): 241-252.

155. Sulem P, Gudbjartsson DF, Stacey SN, Rostrum R Benediktsdottir, Katja $\mathrm{K}$ Aben, et al. (2007) Genetic determinants of hair, eye and skin pigmentation in Europeans. Nature Genetics, 39(12): 1443-1452.

156. Anderson MG, Smith RS, Hawes NL, Adriana Zabaleta, Bo Chang, et al. (2002) Mutations in genes encoding melanosomal proteins cause pigmentary glaucoma in DBA/2J mice. Nature Genetics 30(1): 81-85.

157. Williams A, Howell GR, Barbay JM, Gregory L Sousa, James E. Morgan, et al. (2013) Retinal ganglion cell dendritic atrophy in DBA/2J glaucoma. PLoS One 8(8): e72282.

158. Libby RT, Anderson MG, Pang IH, Richard S Smith, Abbot F Clark, et al. (2005) Inherited glaucoma in DBA/2J mice: pertinent disease features for studying the neurodegeneration. Visual Neuroscience 22(5): 637648.

159. Urabe K, Aroca P, Tsukamoto K, Mascagna D, Palumbo A, et al. (1994) The inherent cytotoxicity of melanin precursors: a revision, Biochimica et Biophysica Acta (BBA) - Molecular Cell Research 1221(3): 272-278.

160. Lindquist NG, Larsson BS, Stjernschantz, Sjöquist B. (1998) Age-related melanogenesis in the eye of mice, studied by microautoradiography of $3 \mathrm{H}$-methimazole, a specific marker of melanin synthesis. Experimental Eye Research 67(3): 259-264.

161. Lopes VS, Wasmeier C, Seabra MC, Futter CE (2007) Melanosome maturation defect in Rab38-deficient retinal pigment epithelium results in instability of immature melanosomes during transient melanogenesis. Molecular Biology of the Cell 18(10): 3914-3927.

162. Lahola Chomiak AA, Wlater MA (2018) Molecular genetics of pigment dispersion syndrome and pigmentary glaucoma: New insights into mechanisms. Hindawi Journal of Ophthalmology Article ID 5926906, 11 pages.

163. Lahola Chomiak AA, Footz T, Nguyen Phuoc K, Neil GJ, Fan B, et al (2019) Non-Synonymous variants in premelanosome protein (PMEL) cause ocular pigment dispersion and pigmentary glaucoma. Human Molecular Genetics 28(8): 1298-1311.

164. S Swaminathan S, Lu H, Williams RW, Lu L, Jablonski MM (2013) Genetic modulation of the iris transillumination defect: a systems genetics analysis using the expanded family of BXD glaucoma strains. Pigment Cell \& Melanoma Research 26(4): 487-498.

165. O Sullivan TN, Wu XS, Rachel RA (2004) Dsu functions in a MYO5Aindependent pathway to suppress the coat color of dilute mice. Proceedings of the National Academy of Sciences of the United States of America 101(48): 16831-16836.

166. Wu X, Bowers B, Wei Q Kocher B, Hammer JA (1997) Myosin V associates with melanosomes in mouse melanocytes: evidence that myosin V is an organelle motor. Journal of Cell Science 110(7): 847859.

167. Scott GA, Arioka AM, Jacobs SE (2007) Lysophosphatidyl- choline mediates melanocyte dendricity through PKC activation. The Journal of Investigative Dermatology 127(3): 668-675.

168. Anderson MG, Hawes NL, Trantow CM, Chang B, John SWM (2008) Iris phenotypes and pigment dispersion caused by genes influencing pigmentation. Pigment Cell Melanoma Res 21(5): 565-578.

169. Jian Q An Q, Zhu D, Hui K, Liu Y (2014) MicroRNA 340 in involved in UVB induced dendrite formation through the regulation of RhoA Expression in Melanocytes. Mol Cell Biol 34(18): 3407-3420. 
170. Fernandes KA, Harder JM, Williams PA, et al. (2015) Using genetic mouse models to gain insight into glaucoma: past results and future possibilities. Experimental Eye Research 141: 42-56

171. Anderson MG, Smith RS, Hawes NL, Zabaleta A, Chang B, et al. (2002) Mutations in genes encoding melanosomal proteins cause pigmentary glaucoma in DBA/2J mice. Nat Genet 30: 81-85.

172. Anderson MG, Nair KS, Amonoo LA, Mehalow A, Trantow CW, et al. (2008) GpnmbR150X allele must be present in bone marrow derived cells to mediate DBA/2J glaucoma. BMC Genet 9: 30.

173. Mo JS, Anderson MG, Gregory M, Smith RS, Savinova OV, et al. (2003) By altering ocular immune privilege, bone marrow derived cells pathologically contribute to DBA/2J pigmentary glaucoma. J Exp Med 197(10): 1335-1344.

174. Nair KS, Barbay J, Smith RS, Masli S, John SW (2014) Determining immune components necessary for progression of pigment dispersing disease to glaucoma in DBA/2J mice. BMC Genet 15: 42

175. Sugar HS (1966) Pigmentary glaucoma A 25-year review. Am J Ophthalmol 62(3): 499-507.

176. HS S, FA B (1949) Pigmentary glaucoma: a rare clinical entity. Am J Ophthalmol 32(1): 90-92.

177. Scheie HG, Cameron JD (1981) Pigment dispersion syndrome: a clinical study. The Br J Ophthalmol 65(4): 264-269.

178. Farrar SM, Shields MB (1993) Current concepts in pigmentary glaucoma Survey of Ophthalmology 37(4): 233-252.

179. Costa VP, Gandham S, Smith M, Spaeth GL (1994) The effects of peripheral iridectomy on pigmentary glaucoma, ArquivosBrasileiros de Oftalmologia 57: 4.

180. Costa VP, Gandham S, Spaeth GL (1994) the effect of nd-yag laser iridotomy on pigmentary glaucoma patients-a prospective-study. Investi Ophthalmol Vis Sci 35: 1852.

181. Georgopoulos GT, Papaconstantinou DS, Patsea LE et al. (2001) Laser iridotomy versus low dose pilocarpine treatment in patients with pigmentary glaucoma. IOVS 42: S817.

182. Zhang SX, Sanders E, Flieser SJ, Wang J (2014) Endoplasmic Reticulum Stress and the unfolded protein response in retinal degeneration. Exp Eye Res 125: 30-40.

183. Khawaja AP, Cooke Bailey JN, Wareham NJ, Scott RA, Simcoe M, et al. (2018) Genome-wide analyses identify 68 new loci associated with intraocular pressure and improve risk prediction for primary openangle glaucoma. Nat Genet 50(6): 778-782

184. Kwon YH, Fingert JH, Kuehn MH, Alward WL (2009) Primary openangle glaucoma. N Engl J Med 360(11): 1113-1124.

185. Kang JH, Boumenna T, Stein JD, Khawaja A, Rosner BA, et al. (2019) Association of statin use and high serum cholesterol levels with risk of primary open-angle glaucoma. JAMA Ophthalmol 137(7): 756-765.

186. Bailey JN, Loomis SJ, Kang JH, Allingham RR, Gharahkhani P, et al (2016) Genome-wide association analysis identifies TXNRD2, ATXN2 and FOXC1 as susceptibility loci for primary open-angle glaucoma. Nat Genet 48(2): 189-194.

187. Tezel, G, Hernandez R, Wax M B (2000) Immunostaining of heat shock proteins in the retina and optic nerve head of normal and glaucomatous eyes. Arch Ophthalmol 118(4): 511-518.

188. Oksala NKJ, Ekmekci FG, Ozsoy E, Kirankaya S, Kokkola T, et al. (2014) Natural thermal adaptation increases heat shock protein levels and decreases oxidative stress. Redox Biol 3: 25-28.

189. Ryhanen T, Hyttinen JMT, Kopitz J, Rilla K, Kuusisto E, et al. (2009) Corsstalk between HSP70 molecular chaperone, lysosomes, proteasomes in autophagy-mediated proteolysis in human retinal pigment epithelial cell. J Cell Mol Med 13(9B): 3616-3631.

190. Rabanal Ruiz Y, Korolchuk VI (2018) mTORC1 and nutrient homeostasis: the central role of the lysosome. Int J Mol Sci 19(3): 818.
191. Sinha D, Valapala M, Shang P, Hose S, Grebe R, et al. (2016) Lysosomes regulators of autophagy in the retinal pigment epithelium. Exp Eye Res 144: 46-53.

192. Zugel U, Kaufmann SH (1999) Role of heat shock proteins in protection from and pathogenesis of infectious diseases. Clin Microbiol Rev 12 : 19-39.

193. Kaufmann SH, Schoel B, van Embden JD, Koga, T, Wand Wurttenberger A Munk ME et al. (1991) Heat-shock protein 60: Implications for pathogenesis of and protection against bacterial infections. Immunol Rev 121: 67-90.

194. Binder RJ (2014) Functions of heat shock proteins in pathways of the innate and adaptive immune system. J Immunol 193(12): 5765-5771.

195. Castellino F, Boucher PE, Eichelberg K, Mayhew M, Rothman JE, et al. (2000) Receptor-mediated uptake of antigen/heat shock protein complexes results in major histocompatibility complex class I antigen presentation via two distinct processing pathways. J Exp Med 191(11): 1957-1964.

196. Massa M, Passalia M, Manzoni SM, Campanelli R, Ciardelli L, et al. (2007) Differential recognition of heat-shock protein dnaJderived epitopes by effector and Treg cells leads to modulation of inflammation in juvenile idiopathic arthritis. Arthritis Rheum 56 (5): 1648-1657.

197. Tukaj S, Kaminski M (2019) Heat Shock Proteins in therapy of autoimmune diseases: too simple to be true? Cell Stress and Chaperones 24(3): 475-479.

198. Wax MB, Barrett DA, Pestronk A (1994) Increased incidence of paraproteinemia and autoantibodies in patients with normal-pressure glaucoma. Am J Ophthalmol 117(5): 561-568.

199. Wax MB, Tezel G, Edward PD (1998) Clinical and ocular histopathological findings in a patient with normal-pressure glaucoma. Arch Ophthalmol 116(8): 993-1001

200. Wax MB, Tezel G, Kawase K, Kitazawa Y (2001) Serum autoantibodies to heat shock proteins in glaucoma patients from Japan and the United States. Ophthalmology 108(2): 296-302.

201. Tezel G, Wax MB (2000) The mechanisms of hsp27 antibody-mediated apoptosis in retinal neuronal cells. J Neurosci 20(10): 3552-3562.

202. Wax MB, Tezel G, Yang J, Peng G, Patil RV, et al. (2008) Induced autoimmunity to heat shock proteins elicits glaucomatous loss of retinal ganglion cell neurons via activated T-cell-derived fas-ligand. J Neurosci 28(46): 12085-12096.

203. Joachim SC, Wax MB, Seidel P, Pfeiffer N, Grus FH (2010) Enhanced Characterization of Serum Autoantibody Reactivity Following HSP 60 Immunization in a Rat Model of Experimental Autoimmune Glaucoma. Curr Eye Res 35(10): 900-908.

204. Sakai M, Sakai H, Nakamura Y, Fukuchi T, Sawaguchi S (2003) Immunolocalization of heat shock proteins in the retina of normal monkey eyes and monkey eyes with laser-induced glaucoma. Jpn J Ophthalmol 47: 42-52.

205. Kalesnykas G, Niittykoski M, Rantala J, Miettinen R, Salminen A, et al (2007) The expression of heat shock protein 27 in retinal ganglion and glial cells in a rat glaucoma model. Neuroscience 150(3): 692-704.

206. Lindquist S, Craig EA (1988) the heat-shock proteins. Ann Rev Genet 22: 631-677.

207. Bruey JM, Ducasse C, Bonniaud P, Ravagnan L, Susin SA, et al. (2000) Hsp27 negatively regulates cell death by interacting with cytochrome c. Nat Cell Biol 2(9): 645-652.

208. Mosser DD, Caron AW, Bourget L, Denis-Larose C, Massie B (1997) Role of the human heat shock protein hsp70 in protection against stressinduced apoptosis. Mol Cell Biol 17(9): 5317-5327.

209. Mao YW, Liu JP, Xiang H, Li DW (2004) Human alphaA- and alphaBcrystallins bind to Bax and Bcl-X(S) to sequester their translocation during staurosporine-induced apoptosis. Cell Death Differ. 11(5): 512526. 
210. Sreekumar PG, Kannan R, Kitamura M, Spee C, Barron E, et al. (2010) alphaB crystallin is apically secreted within exosomes by polarized human retinal pigment epithelium and provides neuroprotection to adjacent cells. PLoS ONE 5(10): e12578.

211. Kamradt MC, Chen F, Cryns VL (2001) The small heat shock protein alpha B-crystallin negatively regulates cytochrome c- and caspase-8dependent activation of caspase- 3 by inhibiting its autoproteolytic maturation. J Biol Chem 276(19): 16059-16063.

212. Thanos S, Bohm MR, Meyer zuhorste M, Prokosch Willing V, Hennig M, et al. (2014) Role of crystallins in ocular neuroprotection and axonal regeneration. Prog Retinal Eye Res. 42: 145-161.

213. Chen H, Cho KS, Vu THK, Shen CH, Kaur M, et al. (2018) Commensal microflora-induced $\mathrm{T}$ cell responses mediate progressive neurodegeneration in glaucoma. Nat Commun 9(1): 3209.

214. Asea A, Kraeft SK, Kurt Jones, EA Stevenson, MA Chen, LB et al. (2000) HSP70 stimulates cytokine production through a CD14-dependant pathway, demonstrating its dual role as a chaperone and cytokine. Nat Med 6(4): 435-442.

215. Jin C, Cleveland JC, Ao L, Li J, Zeng Q, et al. (2014) Human myocardium releases heat shock protein 27 (HSP27) after global ischemia: The proinflammatory effect of extracellular HSP27 through toll-like receptor (TLR)-2 and TLR4. Mol Med 20(1): 280-289.

216. Lamb JR, Young DB (1990) T cell recognition of stress proteins. A link between infectious and autoimmune disease. Mol Biol Med 7(4): 311321.

217. Benagiano M, Elios MM, Amedei A, Azzurri A, Van Der Zee R, et al. (2005) Human 60-kDa heat shock protein is a target autoantigen of T cells derived from atherosclerotic plaques. J Immunol 174: 6509-6517.

218. Tamm ER, Russel P, Johnson DH, Piatigorsky J. (1966) Human and monkey trabecular meshwork accumulate alphabeta- crystallin in response to heat shock and oxidative stress. Investig Ophthal and Vis Sci 37(12): 2402-2413

219. Heijl A, Leske MC, Bengtsson B, Leslie Hyman, Boel Bengtsson, et al (2002) Reduction of intraocular pressure and glaucoma progression: results from the early manifest glaucoma trial. Arch Ophthalmol 120(10): 1268-1279.

220. Leske MC, Heijl A, Hussein M, Mohamed Hussein, Bo Bengtsson, et al. (2003) Factors for glaucoma progression and the effect of treatment: the early manifest glaucoma trial. Arch Ophthalmol 121(1): 48-56.

221. Diskin S, Kumar J, Cao Z, Joel S Schuman, Tim Gilmartin, et al. (2006) Detection of differentially expressed glycogenes in trabecular meshwork of eyes with primary open-angle glaucoma. Invest Ophthalmol Vis Sci 47:1491-1499.

222. Wang N, Chintala S K, Fini ME, Schuman JS (2001) Activation of a tissue-specific stress response in the aqueous outflow pathway of the eye defines the glaucoma disease phenotype. Nat Med 7(3): 304-309.

223. Izzotti A, Longobardi M, Cartiglia C, Sacca SC (2010) Proteome alterations in primary open angle glaucoma aqueous humor. J Proteome Res 9(9): 4831-4838.

224. Gonzalez Iglesias H, Alvarez L, Garcia M, Julio Escribano, Pedro Pablo et al. (2014) Comparative proteomic study in serum of patients with primary open-angle glaucoma and pseudoexfoliaiton glaucoma. Proteom 98: 65-78.

225. Acott TS, Kelley MJ (2008) Extracellular matrix in the trabecular meshwork. Exp Eye Res 86(4): 543-561.

226. Hann CR, Springett MJ, Wang X, Johnson DH (2001) Ultrastructural localization of collagen IV, fibronectin, and laminin in the trabecular meshwork of normal and glaucomatous eyes. Ophthalmic Res 33(6): 314-324.

227. Alexander JP, Samples JR, Acott TS (1998) Growth factor and cytokine modulation of trabecular meshwork matrix metalloproteinase and TIMP expression. Curr Eye Res 17(3): 276-285.
228. Wordinger RJ, Lambert W, Agarwal R, Talati M, Clark AF (2000) Human trabecular meshwork cells secrete neurotrophins and express neurotrophin receptors (Trk). Invest Ophthalmol Vis Sci 41(12): 38333841.

229. Alexander JP, Samples J, Van Buskirk EM, Acott TS (1991) Expression of matrix metalloproteinases and inhibitor by human trabecular meshwork. Invest Ophthalmol Vis Sci 32(1): 172-180.

230. Sacca SC, Centofanti M, Izotti A (2012) New proteins as vascular Biomarkers in primary open angle glaucomatous aqueous humor Invest Ophthalmol Vis Sci 53(7): 4242-4253.

231. Micera A, Quaranta L, Esposito G, Floriani I, Pocobelli S, et al. (2016) Differential Protein Expression Profiles in Glaucomatous Trabecular Meshwork: An Evaluation Study on a Small Primary Open Angle Glaucoma Population. Adv Ther 33(2): 252-267.

232. Tanito M, Kaidzu S, Takai Y, Ohira A (2016) Associaton between systemic oxidative stress and visual field damage in open angle glaucoma. Scientific Reports 6: 25792.

233. Ueda J, Wentz Hunter K, Beatrice Y, Yue JT (2002) Distribution of Myocilin and Extracellular Matrix Components in Juxtacanalicular Tissue of Human Eyes. Invest Ophthal and Vis Sci 43(4): 1068-1076.

234. Hann CR, Springett MJ, Johnson DH (2001) Antigen retrieval of basement membrane proteins from archival eye tissues. J Histochem Cytochem 49: 475-482.

235. Gong H, Trinkaus Randall V, Freddo TF (1989) Ultrastructura immunocytochemical localization of elastin in normal human trabecular meshwork. Curr Eye Res 8(10): 1071-1082.

236. Marshall GE, Konstas AG, Lee WR (1990) Immunogold localization of type IV collagen and laminin in the aging human outflow system. Exp Eye Res 51: 691-699.

237. Callaghan J, Cassidy PS, Humphries P (2017) Open angle glaucoma: therapeutically targeting the extracellular matrix of conventional outflow pathway. Expert opin Ther Targets 21(11): 1037-1050.

238. Clark AF, Wilson K, McCartney MD, Miggans ST, Kunkle M, et al. (1994) Glucocorticoid-induced formation of cross-linked actin networks in cultured human trabecular meshwork cells. Invest Ophthalmol Vis Sci 35: 281-294.

239. Last JA, Pan T, Ding Y, Reilly CM, Keller K, et al. (2011) Elastic modulus determination of normal and glaucomatous human trabecular meshwork. Invest Ophthalmol Vis Sci 52: 2147-2152.

240. Chang J, Stamer WD, Bertrand J, Read AT, Marando CM et al. (2015) Role of nitric oxide in murine conventional outflow physiology. Am J Physiol Cell Physiol 309(4): C205-C214

241. Hood JD, C J Meininger, M Ziche, H J Granger (1998) VEGF upregulates ecNOS message, protein, and NO production in human endothelial cells. Am J Physiol 274(3): H1054-H1058.

242. Kroll J, Waltenberger J (1998) VEGF-A induces expression of eNOS and iNOS in endothelial cells via VEGF receptor-2 (KDR). BiochemBiophys Res Commun 252(3): 743-746.

243. Nathanson JA, McKee M (1995) Identification of an extensive system of nitric oxide-producing cells in the ciliary muscle and outflow pathway of the human eye. Investig Ophthal Vis Sci 36(9): 1765-1773.

244. Schneemann A, Dijkstra BG, Van Den Berg TJ, Kamphuius W, Hoyng PFJ, et al. (2002) Nitric oxide/guanylate cyclase pathways and flow in anterior segment perfusion. Graefe's Arch Clin Exp Ophthalmol 240(11): 936-941.

245. Dismuke WM, Liang J, Overby D, Stamer WD, et al. (2014) Concentrationrelated effects of nitric oxide and endothelin-1 on human trabecular meshwork cell contractility. Exp Eye Res 120: 28-35.

246. Dismuke WM, Mbadugha CC, Ellis DZ (2008) NO-induced regulation of human trabecular meshwork cell volume and aqueous humor outflow facility involve the BKCa ion channel. Am J Physiol Cell Physiol. 294(6): C1378-C1386 
247. Michel T, Loscalzo J (2015) Nitroglycerin and nitric oxide-a rondo of themes in cardiovascular therapeutics. N Engl J Med 373(18): 17881789.

248. Gresele P, Marzotti S, Guglielmini G, Momi S, Gianini S, et al. (2010) Hyperglycemia-induced platelet activation in type 2 diabetes is resistant to aspirin but not to a nitric oxide-donating agent. Diabetes Care 33(6): 1262-1268.

249. Aliancy J, Stamer WD, Wirostko B, (2017) A Review of Nitric Oxide for the Treatment of Glaucomatous Disease. Ophthalmol Ther 6(2): 221 232.

250. Khoobehi B, Chiroli V, Ronchetti D, Miglietta D, Thompson H, et al (2011) Enhanced oxygen saturation in optic nerve head of nonhuman primate eyes following the intravitreal injection of NCX 434, an innovative nitric oxide-donating glucocorticoid. J Ocul Pharmacol Ther 27(2): 115-121

251. Araie M, Sforzolini BS, Vittitow J, Weinreb RN (2015) Evaluation of the effect of latanoprostenebunod ophthalmic solution, $0.024 \%$ in lowering intraocular pressure over $24 \mathrm{~h}$ in healthy Japanese subjects. Adv Ther 32(11): 1128-1139.

252. Weinreb R, Ong T, Sforzolini BS, Vittitow JL, Singh K Kaufman PL (2014) A randomised, controlled comparison of latanoprostenebunod and latanoprost $0.005 \%$ in the treatment of ocular hypertension and open angle glaucoma: the VOYAGER study. Br J Ophthalmol 99(6): 738-745.

253. Kazuhide Kawase, Jason L Vittitow, Robert N Weinreb, Makoto Araie, The Group F (2016) Long-term safety and efficacy of latanoprostenebunod $0.024 \%$ in Japanese subjects with open-angle glaucoma or ocular hypertension: the JUPITER study. Adv Ther 33(9): 1612-1627.

254. Prasanna GB, Li B, Mogi M, Rice DS (2016) Pharmacology of nove intraocular pressure-lowering targets that enhance conventional outflow facility: pitfalls, promises and what lies ahead? Eur J Pharmacol 787: 47-56.

255. Pervan CL (2017) Smad-independent TGF- $\beta 2$ signaling pathways in human trabecular meshwork cells. Exp Eye Res 158: 137-145.

256. Ozcan AA, Ozdemir NA, Canataroglu A (2004) the aqueous levels of TGF- $\beta 2$ in patients with glaucoma. Int Ophthalmol 25(1): 19-22.

257. Gottanka J, Chan D, Eichhorn M, Lutjen-Drecoll E, Ethier CR (2004) Effects of TGF- $\beta 2$ in perfused human eyes. Invest Ophthalmol Visual Sci 45(1): 153-158.

258. Han H, Wecker T, Grehn F, Schlunck G (2011) Elasticity-dependent modulation of TGF- $\beta$ responses in human trabecular meshwork cells. Invest Ophthalmol Visual Science 52(6): 2889-2896.

259. McDowell CM, Tebow HE, Wordinger RJ, Clark AF (2013) Smad3 is necessary for transforming growth factor- beta2 induced ocular hypertension in mice. Exp Eye Res 116: 419-423.

260. Liton P B, Li G, Luna C, Gonzalez P, Epstein DL (2009) Cross-talk between TGF- $\beta 1$ and IL- 6 in human trabecular meshwork cells. Mol Vis 15: $326-334$

261. Kang MH, Oh D, Kang J, Rhee DJ (2013) Regulation of SPARC by transforming growth factor $\beta 2$ in human trabecular meshwork Investig Ophthalmol Vis Sci 54(4): 2523-2525.

262. Yamashita M, Fatyol K, Jin CX, Wang X, Liu Z, et al. (2008) TRAF6 mediates Smad-independent activation of JNK and $\mathrm{p} 38$ by TGF- $\beta$. Mol Cell 31(6): 918-924.

263. Sorrentino A, Thakur N, Grimsby S, Anders Marcusson, Verena von Bulow, et al. (2008) The type I TGF- $\beta$ receptor engages TRAF6 to activate TAK1 in a receptor kinase- independent manner. Nat Cell Biol 10(10): 1199-1207.

264. Filla MS, Schwinn MK, Sheibani N, Kaufman PL, Peters DM (2009) Regulation of cross-linked actin network (CLAN) formation in human trabecular meshwork (HTM) cells by convergence of distinct $\beta 1$ and $\beta 3$ integrin pathways. Investigative Ophthalmology \& Visual Science 50(12): 5723-5731.

265. Pattabiraman PP, Rao PV (2010) Mechanistic basis of Rho GTPaseinduced extracellular matrix synthesis in trabecular meshwork cells.

\section{AJP: Cell Physiology 298(3): C749-C763.}

266. Honjo M, Tanihara H, Inatani M, T Sawamura, B Y Yue, et al. (2001) Effects of Rho-associated protein kinase inhibitor Y-27632 on intraocular pressure and outflow facility. Investigative Ophthalmology and Visual Science 42(1): 137-144

267. Levkovitch Verbin H (2015) Retinal ganglion cell apoptotic pathway in glaucoma: initiating and downstream mechanisms, Prog Brain Res 220: 37-57.

268. Ham J, Eilers A, Whitfield J, Neame SJ Shah B (2000) c-Jun and the transcriptional control of neuronal apoptosis. Biochem Pharmacol 60(8): 1015-1021.

269. Johnson EC, Guo Y, Cepurna WO, Morrison JC (2009) Neurotrophin roles in retinal ganglion cell survival: lessons from rat glaucoma models. Exp Eye Res 88(4): 808-815.

270. Dudek H, Datta SR, Franke TF, M J Birnbaum, R Yao, et al. (1997) Regulation of neuronal survival by the serine-threonine protein kinase Akt. Science 275(5300): 661-665.

271. M K Barthwal, Praveen Sathyanarayana, Chanakya N Kundu, Basabi Rona, Chandan Sharma, et al. (2003) Negative regulation of mixed lineage kinase 3 by protein kinase B/AKT leads to cell survival. J Bio Chem 278(6): 3897-3902

272. Levkovitch Verbin H, Harizman N, Dardik R, Nisgav S, Vander S, et al. (2007) Regulation of cell death and survival pathways in experimental glaucoma. Exp Eye Res 85(2): 250-258.

273. Vander S, Levkovitch Verbin H (2012) Regulation of cell death and survival pathways in secondary degeneration of the optic nerve a longterm study. Curr Eye Res 37(8): 740-748.

274. Zhu RL, Cho KS, Guo CY, Chew J, Chen DF, et al. (2013) intrinsic determinants of optic nerve regeneration. Chin Med J126 (13): 25432547.

275. Levkovitch Verbin H, Dardik R, Vander S, Nisgav Y, Kalev Landoy M, et al. (2006) Experimental glaucoma and optic nerve transection induce simultaneous upregulation of proapoptotic and prosurvival genes, Invest Ophthalmol Vis Sci 47(6): 2491-2497.

276. Levkovitch Verbin H, Vander S, Makarovsky D, Lavinsky F (2013) Increase in retinal ganglion cells' susceptibility to elevated intraocular pressure and impairment of their endogenous neuroprotective mechanism by age. Mol Vis 19: 2011-2022.

277. Wojda U, Salinska E, Kuznicki J (2008) Calcium ions in neuronal degeneration. IUBMB Life 60(9): 575-590.

278. Huang W, Fileta JB, Dobberfuhl A, Yan Guo, Gina Kwon et al. (2005) Calcineurin cleavage is triggered by elevated intraocular pressure and calcineurin inhibition blocks retinal ganglion cell death in experimental glaucoma. Proc Natl Aca Sci 102(34): 12242-12247.

279. Gumy LF, Tan CL, Fawcett JW (2010) The role of local protein synthesis and degradation in axon regeneration. Experimental Neurology 223(1): 28-37.

280. Ribas VT, Lingor P, (2016) Calcium channel inhibition-mediated axonal stabilization improves axonal regeneration after optic nerve crush. Neural Regeneration Research 11(8): 1245-1246.

281. Knoferle J, Koch JC, Ostendorf T, et al. (2010) Mechanisms of acute axonal degeneration in the optic nerve in vivo. Proc Natl Acad Sci 107(13): 6064-6069.

282. Nafissi N, Foldvari M (2016) Neuroprotective therapies in glaucoma: I. Neurotrophic factor delivery. Wiley Interdisciplinary Reviews: Nanomedicine and Nanobiotechnology 8(2): 240-254.

283. Liu Y, Gong Z, Liu L, Sun H (2010) Combined effect of olfactory ensheathing cell (OEC) transplantation and glial cell line-derived neurotrophic factor (GDNF) intravitreal injection on optic nerve injury in rats. Molecular Vision 16: 2903-2910.

284. Sun H, Wang Y, Pang IH, et al. (2011) Protective effect of a JNK inhibitor against retinal ganglion cell loss induced by acute moderate ocular hypertension. Molecular Vision 17: 864-875.

285. Tezel G, Yang X, Yang J, Wax MB (2004) Role of tumor necrosis factor 
receptor-1 in the death of retinal ganglion cells following optic nerve crush injury in mice. Brain Res 996(2): 202-212.

286. Shen W, Han Y, Huang B, Qi Y, Xu l, et al. (2015) Micro RNA-483-3p inhibits extracellular matrix production by targeting smad 4 in human Trabecular Meshwork Cells. Invest Opthalmol Vis Sci 56: 8419-8427.

287. Nucci C, Martucci A, Gianini C, Marrone LA, Bagetta G, et al. (2018) Neuroprotective agents in the management of glaucoma. Eye 32: 938945.

288. Guo L, Cordeiro MF (2008) Assessment of neuroprotection in the retina with DARC. Prog Brain Res 173: 437-450.

289. Russo R, Cavaliere F, Rombolà L, Gliozzi M, Cerulli A, et al. Rational basis for the development of coenzyme $\mathrm{Q} 10$ as a neurotherapeutic agent for retinal protection. Prog Brain Res 2008(173): 575-582.
290. Fioravanti M, Yanagi M (2005) Cytidinediphosphocholine (CDPcholine) for cognitive and behavioral disturbances associated with chronic cerebral disorders in the elderly. Cochrane Database Syst Rev 18: CD000269.

291. Oshitari T, Fujimoto N, Adachi Usami E (2002) Citicoline has a protective effect on damaged retinal ganglion cells in mouse culture retina. Neuroreport 13(16): 2109-2111.

292. Schuettauf F, Rejdak R, Thaler S, Bolz S, Lehaci C, et al. (2006) Citicoline and lithium rescue retinal ganglion cells following partial optic nerve crush in the rat. Exp Eye Res 83(5): 1128-1134.

293. Hayat B, Kapuganti RS, Padhy B, Mohanti PP, Alone DP (2020) Epigenetic silencing of heat shock protein 70 through DNA hypermethylation in pseudoexfoliation syndrome and glaucoma. J Human Genetics 65: 517 529. 